\title{
A SMECTITE DEHYDRATION MODEL IN A SHALLOW SEDIMENTARY BASIN: MODEL DEVELOPMENT
}

\author{
Chen-Wuing LiU ${ }^{1}{ }^{*}$ And Wen-Sheng Lin ${ }^{2}$ \\ ${ }^{1}$ Department of Bioenvironmental Systems Engineering, National Taiwan University, Taipei, Taiwan 106, ROC \\ ${ }^{2}$ Water Resources Agency, Ministry of Economic Affairs, Taipei, Taiwan 106, ROC
}

\begin{abstract}
Traditionally, land subsidence resulting from groundwater over-pumping has often been described by the theory of consolidation. The mechanism of land subsidence due to the dehydration of clay minerals has not been well addressed. Therefore, this study develops a smectite dehydration model to describe the effect of the release of water from the smectite interlayer upon land subsidence. Using a thermodynamic solid-solution model and laboratory studies of clay-water systems, a complete description of the dehydration relationships among the swelling pressure, basal spacing and $m_{\mathrm{w}} / m_{\mathrm{c}}$ in a Na-smectite water system at $25^{\circ} \mathrm{C}$ under variable pressure conditions was derived. Accordingly, the evaluation model of the 'hydration state of smectite', and the 'solid-solution model of smectite dehydration' were formulated rigorously. These two models were applied to quantify the effects of smectite dehydration on the accumulated land subsidence in the Yun Lin offshore industrial infrastructure complex and in the Tai-Shi area. The result reveals that smectite dehydration is of importance in assessing and predicting land subsidence in a shallow sedimentary basin.
\end{abstract}

Key Words — Land Subsidence, Sedimentary Basin, Smectite Dehydration, Thermodynamic Model.

\section{INTRODUCTION}

Land subsidence that results from over-pumping of groundwater proceeds by two main processes - primary consolidation and secondary compression. Primary consolidation is caused by the dissipation of excess pore-water pressure, which gradually increases the effective stress on the soil skeleton. The amount of primary consolidation due to the increase of effective stress can be determined using Terzaghi's theory of consolidation (Terzaghi, 1925). After the excess porewater pressure dissipates, secondary compression develops slowly and continuously, including slippage of soil particles, release of water from soil micro-fabric elements, expulsion of water from clay minerals and the surface interaction of the readjustment of the positions of the attached cations. Of these processes, the dehydration of smectite is an important part of secondary compression. The transient void ratio against the effective stress in the secondary compression indicates that as the effective stress is applied for longer, the soil particles are compacted more densely (Mitchell, 1993). Das (1990) suggested the use of a coefficient of secondary compression to assess the secondary compression. The method is too simple to reflect the transient behavior of soil compression, and the assumption that the secondary compression occurs only following the completion of primary consolidation

\footnotetext{
* E-mail address of corresponding author:

1cw@gwater.agec.ntu.edu.tw

DOI: $10.1346 / C C M N .2005 .0530107$
}

may not hold. The effective stress drives the primary and secondary compactions.

As soil compaction begins, dissipation of excess pore pressure and the rearrangement of the soil structure may occur concurrently. The correct approach when evaluating soil compaction is to formulate the governing equations of the coupling processes and solve them analytically or numerically. Mitchell (1993) showed that the flow equation for the dynamic dissipation of excess pore water, the clay dehydration equation and the constitutive equation of soil/water rheology are difficult to develop and solve. Biot $(1941,1955)$ developed a three-dimensional elastic model coupled with excess pore-water pressure to evaluate primary soil compaction. Bethke (1986) proposed a compaction model that considered various effects, including the release of water due to clay dehydration. However, Bethke's model did not incorporate Terzagh's or Biot's principle of effective stress, and the mechanics of compaction were not addressed rigorously. Audet (1995) developed a one-dimensional model of the gravitational compaction of deep sediment layers in which the sediments undergo a thermally activated dehydration reaction of smectite to illite, releasing pore fluid at depth. Chemically released water can increase the excess pore pressure by as much as $30 \%$ for a relatively impermeable sediment. If sediments overlie a permeable base, then fluid can flow out of the sediments, relieving pore pressure throughout the sedimentary column.

In a shallow sedimentary basin, the over-pumping of groundwater may partially dehydrate the clay minerals; however, the transition of semectite to illite is unlikely to occur because of the small temperature effect. Liu and 
others (2001) applied the smectite dehydration theory of Ramson and Helgeson (1994a, 1994b, 1995) to evaluate the effect of clay dehydration on the cumulative amount of land subsidence in the Yun Lin coastal area in Taiwan. However, they did not consider the non-linear relationships between both the swelling pressure and the basal spacing and the ratio of the mass of water to the mass of smectite. The computed subsidence due to the smectite dehydration is overestimated.

The aim of this study was to develop a rigorous thermodynamic model of smectite dehydration for evaluating subsidence in a shallow sedimentary basin. The thermodynamics of interlayer water and the relationship between swelling pressure and basal spacing for different hydration states of smectite are used to develop an interlayer hydration-state model and a solidsolution model of interlayer dehydration. The model developed was used to quantify the effects of dehydration of smectite on subsidence in the Yun-Lin offshore industrial infrastructure complex and in the Tai-Shi area in Yun Lin, Taiwan.

\section{SMECTITE DEHYDRATION THEORY}

\section{Hydration/dehydration of smectite}

The isomorphic substitution of $\mathrm{Al}^{3+}$ and $\mathrm{Mg}^{2+}$ in smectite octahedral sites, or of $\mathrm{Si}^{4+}$ by $\mathrm{Al}^{3+}$ in smectite tetrahedral sites generates an excess negative charge on the smectite structure. Excess negative structural charge is compensated for by the adsorption of cations on the smectite layers. In the presence of water, the compensating cations on smectite layers may easily be exchanged for other cations (such as $\mathrm{Ca}^{2+}, \mathrm{Mg}^{2+}, \mathrm{Na}^{+}$ or $\mathrm{K}^{+}$) when available in solution. Moreover, the hydration of smectite will create a negative hydroxyl surface charge (such as in Si-OH or Al-OH). The polar structure of water molecules is such that water is strongly adsorbed onto the surface of smectite. If the water is adsorbed by the interlayer of smectite, it is called interlayer water. Colten-Bradley (1987) stated that the smectite interlayer includes four discontinuous basal spacings of $\sim 10 \AA, \sim 12 \AA, \sim 15.5 \AA$ and $\sim 18.5 \AA$. The $10 \AA$ basal spacing is free from water molecules whereas the $\sim 15.5 \AA$ basal spacing contains 20 wt. $\%$ water (Ransom and Helgeson, 1994a). The hydration state, or the amount of interlayer water, is a function of the extent and location of the 2:1 layer charge (Foster, 1953; Harward and Brindley, 1966), the interlayer cation species (Posner and Quirk, 1964), the vapor pressure (Keren and Shainberg, 1975; Ormerod and Newman, 1983), the temperature (Rowland et al., 1956; Keren and Shainberg, 1980) and the salinity of associated water (Norrish and Quirk, 1954; Posner and Quirk, 1964). Discontinuities in the basal spacings of smectites, observable by X-ray diffraction (XRD), may be induced by changes in vapor pressure, type of interlayer cation, salinity and temperature. These discontinuities are referred to as stepwise changes in the hydration state and occur at basal spacings of $<\sim 20 \AA$.

The hydration condition of the layers of water molecules adsorbed on the smectite increases monotonically from one in increments of one, according to the increase in the wetness. Three driving forces govern the swelling of hydrated smectite including the surface hydration force, the osmotic hydration force and the capillary force, the first two of which are more important than the last. Water molecules adsorbed onto the surface and into interlayer positions cause structural swelling. At low humidity, only the surface adsorbs water molecules and exchangeable cations in the interlayer. It is also free from hydration. As the humidity increases, the exchangeable interlayer cations begin to hydrate and the interlayer spacing increases in a stepwise fashion. As the humidity increases further, the externally adsorbed water molecules become multilayers and fill up exterior micropores. The osmotic hydration force is generated by the chemical potential of the interlayer cations being greater than that of the free ions in bulk solution. As a result, water molecules diffuse into the interlayer region, increase the basal spacing and form a diffusive electrical double layer.

Zhang and Low (1989) determined experimentally the relationship between basal spacing and the ratio of the water mass $\left(m_{\mathrm{w}}\right)$ to the smectite mass $\left(m_{\mathrm{c}}\right)$ in the Na-smectite/water system. As the ratio $m_{\mathrm{w}} / m_{\mathrm{c}}$ increases from 0.0 to $4.5 \mathrm{~g} / \mathrm{g}$, the basal spacing increases from $\sim 10 \AA$ to $\sim 110 \AA$. However, as $m_{\mathrm{w}} / m_{\mathrm{c}}$ increases from 0.6 to $1.0 \mathrm{~g} / \mathrm{g}$, basal spacings jump discontinuously from $\sim 19 \AA$ to $32 \AA$. The discontinuous jump may be caused by the increase in the number of exchangeable cations on the negatively charged smectite surface as the interlayer hydration spacing increases. If the expulsive forces of the interlayer cations exceed the van der Waal's forces, then the attractive forces on the negatively charged surface and the dipole attraction may trigger an unstable discontinuous jump.

Oliphant and Low (1982) measured swelling pressure against the thermodynamic parameters of enthalpy and entropy in a smectite-water system and yielded a regression relationship between the change in swelling pressure and $m_{\mathrm{w}} / m_{\mathrm{c}}$. The relationship is described as

$$
\Pi=-\left(\bar{h}_{\mathrm{w}}-h_{\mathrm{w}}^{0}\right) / \bar{v}_{\mathrm{w}}+T\left(\bar{s}_{\mathrm{w}}-s_{\mathrm{w}}^{0}\right) \bar{v}_{\mathrm{w}}
$$

where $\Pi$ : swelling pressure; $\bar{h}_{\mathrm{w}}$ : enthalpy of water in a smectite water system; $h_{\mathrm{w}}^{0}$ : enthalpy of water in a pure water system; $\bar{v}_{\mathrm{w}}$ : water volume per unit mass of water in a smectite water system; $\bar{s}_{\mathrm{w}}$ : enthalpy of water in a smectite water system; $s_{\mathrm{w}}^{0}$ : enthalpy of water in a pure water system; and $T$ : absolute temperature.

The $\bar{v}_{\mathrm{w}}$ values in Table 1 were taken from Low (1979) who also developed a regression equation using the experimental data of Anderson and Low (1958), as given in equation 2 which is only valid when $\left(m_{\mathrm{w}} / m_{\mathrm{c}}\right)>1$ (Oliphant and Low, 1982). 
Table 1. Thermodynamic data of water enthalpy, entropy and swelling pressure $v s . m_{\mathrm{w}} / m_{\mathrm{c}}$ in a smectite water system at $25^{\circ} \mathrm{C}$ (after Oliphant and Low, 1982).

\begin{tabular}{lccr}
\hline $\begin{array}{l}m_{\mathrm{w}} / m_{\mathrm{c}} \\
(\mathrm{g} / \mathrm{g})\end{array}$ & $\begin{array}{c}-\left(\bar{h}_{\mathrm{w}}-h_{\mathrm{w}}^{0}\right) / \overline{\mathrm{v}}_{\mathrm{w}} \\
(\mathrm{atm})\end{array}$ & $\begin{array}{c}T\left(\bar{s}_{\mathrm{w}}-s_{\mathrm{w}}^{0}\right) / \bar{v}_{\mathrm{w}} \\
(\mathrm{atm})\end{array}$ & \multicolumn{1}{|}{$\begin{array}{c}\Pi \\
(\mathrm{kPa})\end{array}$} \\
\hline 0.25 & 475.29 & -343.5 & 13353.622 \\
0.30 & 142.15 & -52.75 & 9058.455 \\
0.35 & 72.31 & -13.77 & 5931.566 \\
1.50 & 1.11 & 6.19 & 739.673 \\
2.00 & 0.604 & 3.17 & 382.401 \\
3.00 & 0.292 & 1.59 & 190.694 \\
4.00 & 0.182 & 0.888 & 108.418 \\
5.00 & 0.123 & 0.517 & 64.848 \\
6.00 & 0.088 & 0.332 & 42.557 \\
7.00 & 0.074 & 0.226 & 30.398 \\
8.00 & 0.057 & 0.193 & 25.331 \\
10.00 & 0.087 & -0.082 & 0.487 \\
\hline
\end{tabular}

$$
\bar{v}_{w}=1.002 \exp \left[\frac{0.036}{\left(m_{\mathrm{w}} / m_{\mathrm{c}}\right.}\right] \text { for } m_{\mathrm{w}} / m_{\mathrm{c}}>1
$$

In this study, the data on water density $v s$. the $m_{\mathrm{w}} / m_{\mathrm{c}}$ value of Martin (1962) was regressed by Table Curve 2D (SYSTAT, 2001) to yield equation 3 (Figure 3), and thus extend the range of application of $m_{\mathrm{w}} / m_{\mathrm{c}}$

$\rho\left(m_{\mathrm{w}} / m_{\mathrm{c}}\right)=$

$\frac{a_{1}+c_{1}\left(\frac{m_{\mathrm{w}}}{m_{\mathrm{c}}}\right)^{2}+e_{1}\left(\frac{m_{\mathrm{w}}}{m_{\mathrm{c}}}\right)^{4}+g_{1}\left(\frac{m_{\mathrm{w}}}{m_{\mathrm{c}}}\right)^{6}+i_{1}\left(\frac{m_{\mathrm{w}}}{m_{\mathrm{c}}}\right)^{8}+k_{1}\left(\frac{m_{\mathrm{w}}}{m_{\mathrm{c}}}\right)^{10}}{1+b_{1}\left(\frac{m_{\mathrm{w}}}{m_{\mathrm{c}}}\right)^{2}+d_{1}\left(\frac{m_{\mathrm{w}}}{m_{\mathrm{c}}}\right)^{4}+f_{1}\left(\frac{m_{\mathrm{w}}}{m_{\mathrm{c}}}\right)^{6}+h_{1}\left(\frac{m_{\mathrm{w}}}{m_{\mathrm{c}}}\right)^{8}+j_{1}\left(\frac{m_{\mathrm{w}}}{m_{\mathrm{c}}}\right)^{10}}$

where $R^{2}=0.89, a_{1}=1.55, b_{1}=-9.28, c_{1}=-16.66, d_{1}$ $=115.17, e_{1}=146.88, f_{1}=-1176.16, g_{1}=-1200.15 h_{1}$ $=4411.20, i_{1}=4316.69, j_{1}=5.54$, and $k_{1}=7.97$

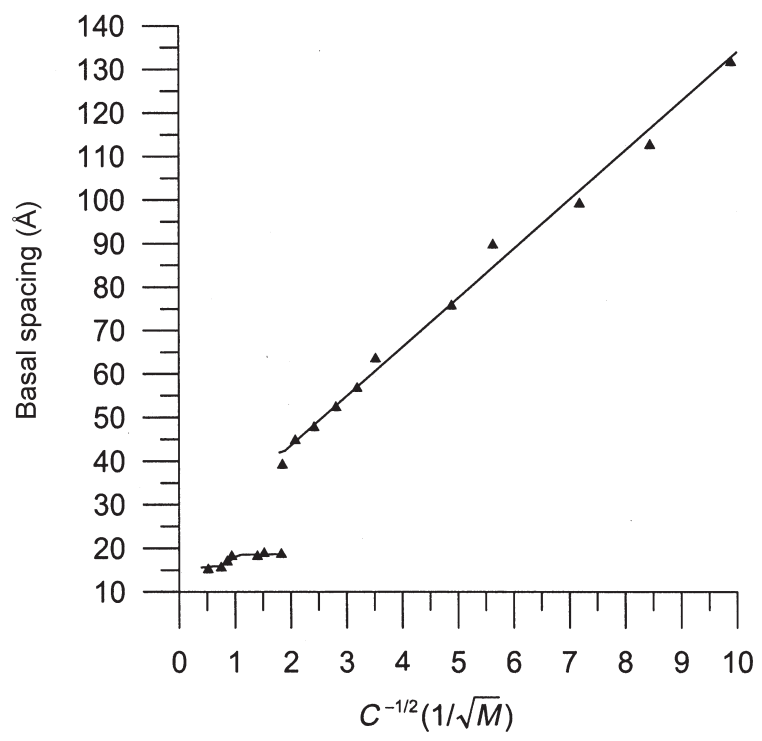

Figure 1. Linear relationship of basal spacing $v s$. the reciprocal of the square root of the ionic concentration $(C)$ in moles $(M)$ of Na-smectite (after Norrish, 1954).

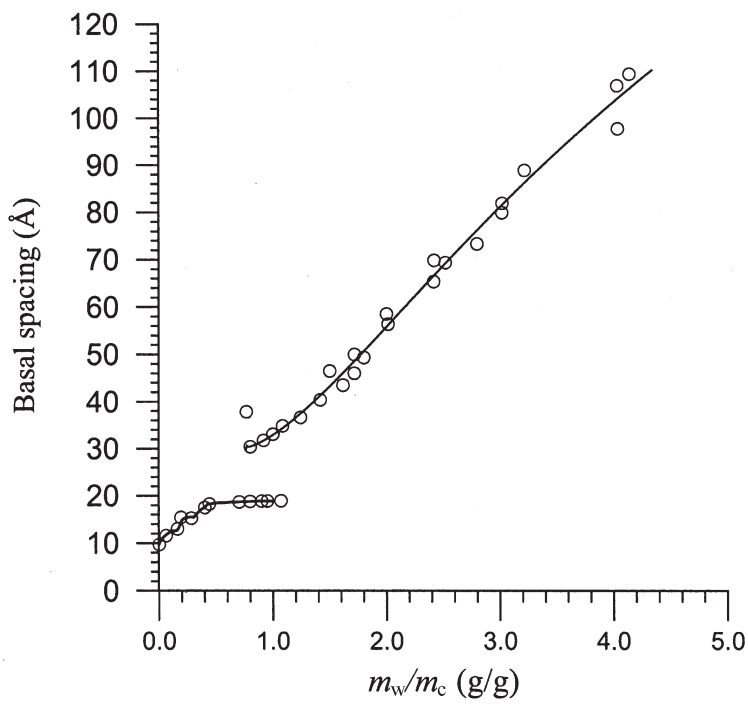

Figure 2. Basal spacing vs. the ratio of water mass $\left(m_{\mathrm{w}}\right)$ to smectite mass $\left(m_{\mathrm{c}}\right)$ in a Na-smectite water system (after Zhang and Low, 1989).

The reciprocal relation $\bar{v}_{\mathrm{w}}=1 / \rho$ is used to yield modified $\bar{v}_{\mathrm{w}}$. Substituting the modified $\bar{v}_{\mathrm{w}}$ in equation 1 yields the swelling pressure. Low (1979) and Oliphant and Low (1982) did not provide experimental data on $\left(\bar{h}_{\mathrm{w}}-h_{\mathrm{w}}^{0}\right)$ for $m_{\mathrm{w}} / m_{\mathrm{c}}$ in the range $0.35-1.5 \mathrm{~g} / \mathrm{g}$. The experimental data for $\bar{h}_{\mathrm{w}}-h_{\mathrm{w}}^{0}$ vs. $m_{\mathrm{w}} / m_{\mathrm{c}}$ shown in Figure 4, and obtained by Zhang and Low (1989), are adopted to describe completely the change in swelling pressure over the full range of $m_{\mathrm{w}} / m_{\mathrm{c}}$; the relationship between $\left(\bar{s}_{\mathrm{w}}-s_{\mathrm{w}}^{0}\right)$ and $m_{\mathrm{w}} / m_{\mathrm{c}}$ (Figure 5) is used to interpolate the $\bar{s}_{\mathrm{w}}-s_{\mathrm{w}}^{0}$ values of $m_{\mathrm{w}} / m_{\mathrm{c}}$ over the range $0.35-1.5 \mathrm{~g} / \mathrm{g}$. Thus, the experimental and interpolated data on swelling pressure over $m_{\mathrm{w}} / m_{\mathrm{c}}$ (Oliphant and

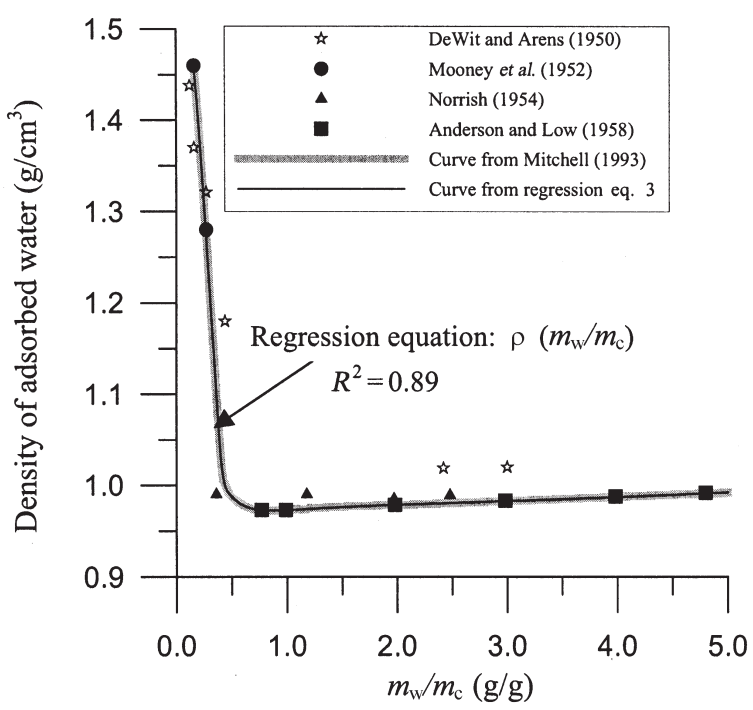

Figure 3. Adsorbed water density vs. $m_{\mathrm{w}} / m_{\mathrm{c}}$ in a Na-smectite water system (after Mitchell, 1993) $m_{\mathrm{w}}$ : mass of water, $m_{\mathrm{c}}$ : mass of smectite. 

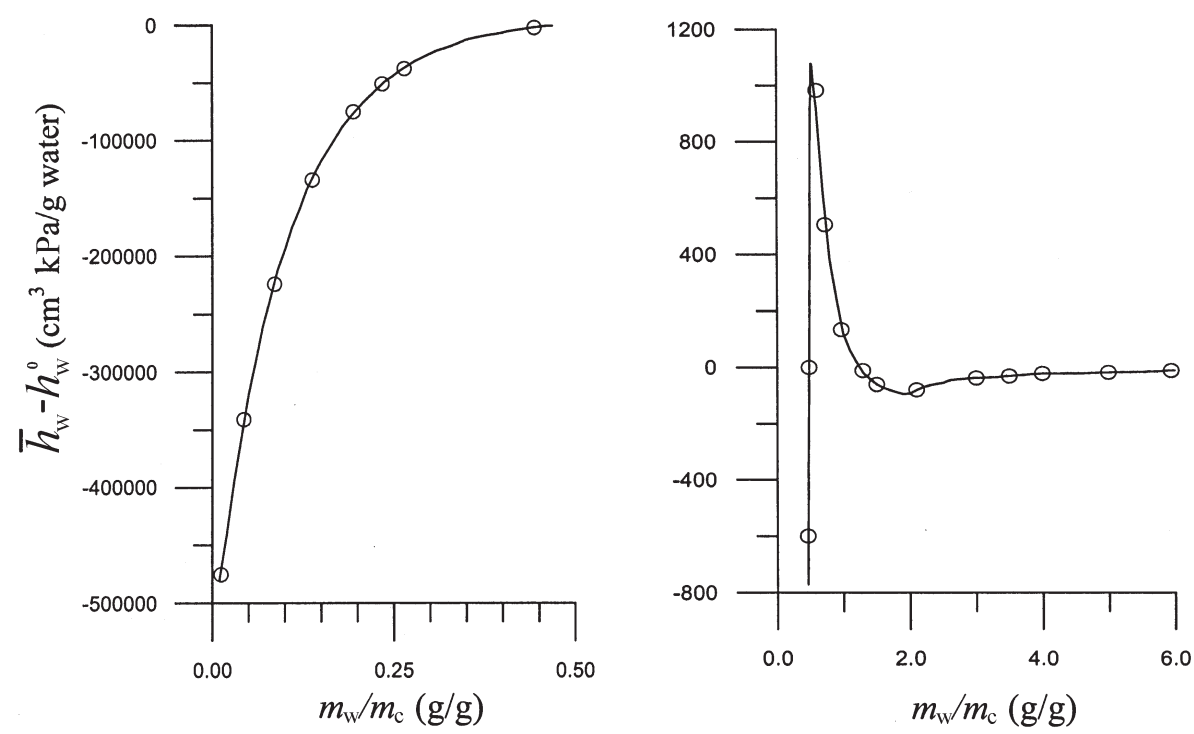

Figure 4. $\left(\bar{h}_{\mathrm{w}}-h_{\mathrm{w}}^{0}\right)$ vs. $m_{\mathrm{w}} / m_{\mathrm{c}}$ in a Na-smectite water system (after Zhang and Low, 1989).

Low, 1982) and the relationship between basal spacing (Zhang and Low, 1989) and $m_{\mathrm{w}} / m_{\mathrm{c}}$ (Figure 2) describe completely the relationships among $m_{\mathrm{w}} / m_{\mathrm{c}}$, basal spacing and the swelling pressure. The basal spacing decreases from 110 to $43 \AA$, and $m_{\mathrm{w}} / m_{\mathrm{c}}$ reduces accordingly from $\sim 4$ to $1.5 \mathrm{~g} / \mathrm{g}$. As the $m_{\mathrm{w}} / m_{\mathrm{c}}$ decreases further, the swelling pressure drops quickly and even becomes negative. The substantial drop of swelling pressure, corresponding to the discontinuous jump is in the range of $m_{\mathrm{w}} / m_{\mathrm{c}}$ from 0.6 to $1.0 \mathrm{~g} / \mathrm{g}$. The mutual interaction energy in the interlayer region explains the negative swelling pressure (Zhang et al., 1995). Figure 7 plots the distribution of the mutual interaction energy against the distance between the interlayers in a hydrated smectite. The region in which smectite swells partially

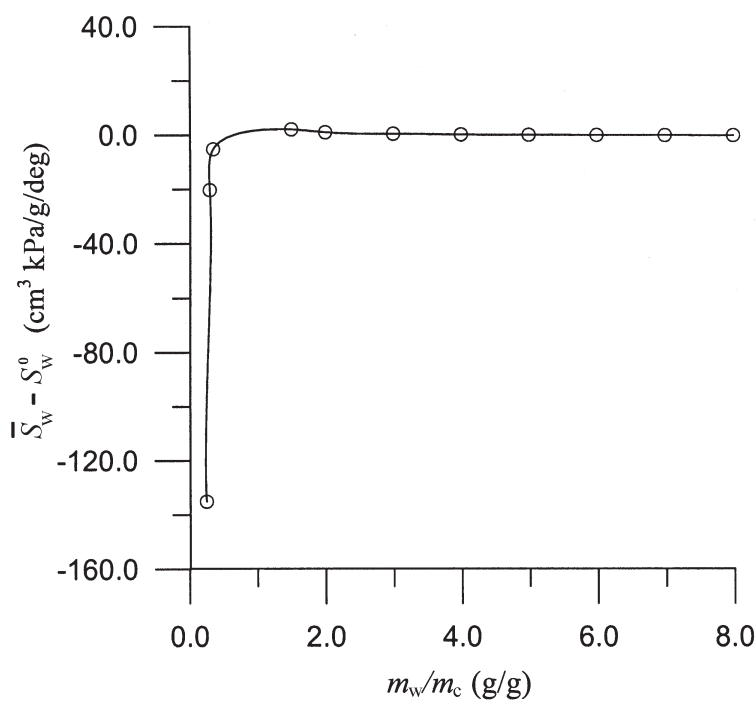

Figure 5. $\left(\bar{s}_{\mathrm{w}}-s_{\mathrm{w}}^{0}\right)$ vs. $m_{\mathrm{w}} / m_{\mathrm{c}}$ in a Na-smectite water system at $25^{\circ} \mathrm{C}$ (after Oliphant and Low, 1982). has a primary energy minimum whereas the region in which smectite swells fully has a secondary energy minimum. The transition from the secondary to the primary energy minimum requires the energy barrier to be climbed.

\section{Solid-solution model}

Theory. Ransom and Helgeson (1994a) described the thermodynamic characteristic of hydrated or dehydrated smectite as the possession or lack of interlayer water. The structure of 2:1 type smectite does not change during dehydration. The interlayer region in the silicate structure can be considered to be a solvent; the water is the solute dissolved in the solvent, and the solution is called a solid-solution. Using $\mathrm{O}_{10}(\mathrm{OH})_{2}$ as a base crystal-chemical unit, Ransom and Helgeson (1989) expressed hydrated $\mathrm{Na}$-smectite $\left(\mathrm{Na}_{0.3} \mathrm{Al}_{1.9} \mathrm{Si}_{4} \mathrm{O}_{10}\right.$ $(\mathrm{OH})_{2} \cdot n \mathrm{H}_{2} \mathrm{O}$, where $n$ is the number of moles of water in the fully hydrated Na-smectite). In this paper we also adopt this model with the modification that Na-smectite is a solid-solution with basal spacings from 10 to $19 \AA$. $\mathrm{Na}^{+}$-rich seawater intrudes upon the coastal groundwater. We also follow the assumption of Ransom and Helgeson (1989) that 2:1-type dioctahedral and trioctahedral Na-smectite exhibit the same thermodynamic solid-solution properties.

The chemical and thermodynamic properties of interlayer water differ from those of pore water. Interlayer water can be considered as water bonded to a mineral, forming a hydrated mineral. When dehydration occurs, the interlayer water will be released from the hydrated smectite to form $\mathrm{H}_{2} \mathrm{O}$ and a homologous anhydrous 2:1 layer-silicate counterpart. This behavior is analogous to the reversible intracrystallization reaction of a solid-solution and is specified by the following equation (Ransom and Helgeson, 1994a, 1995). 


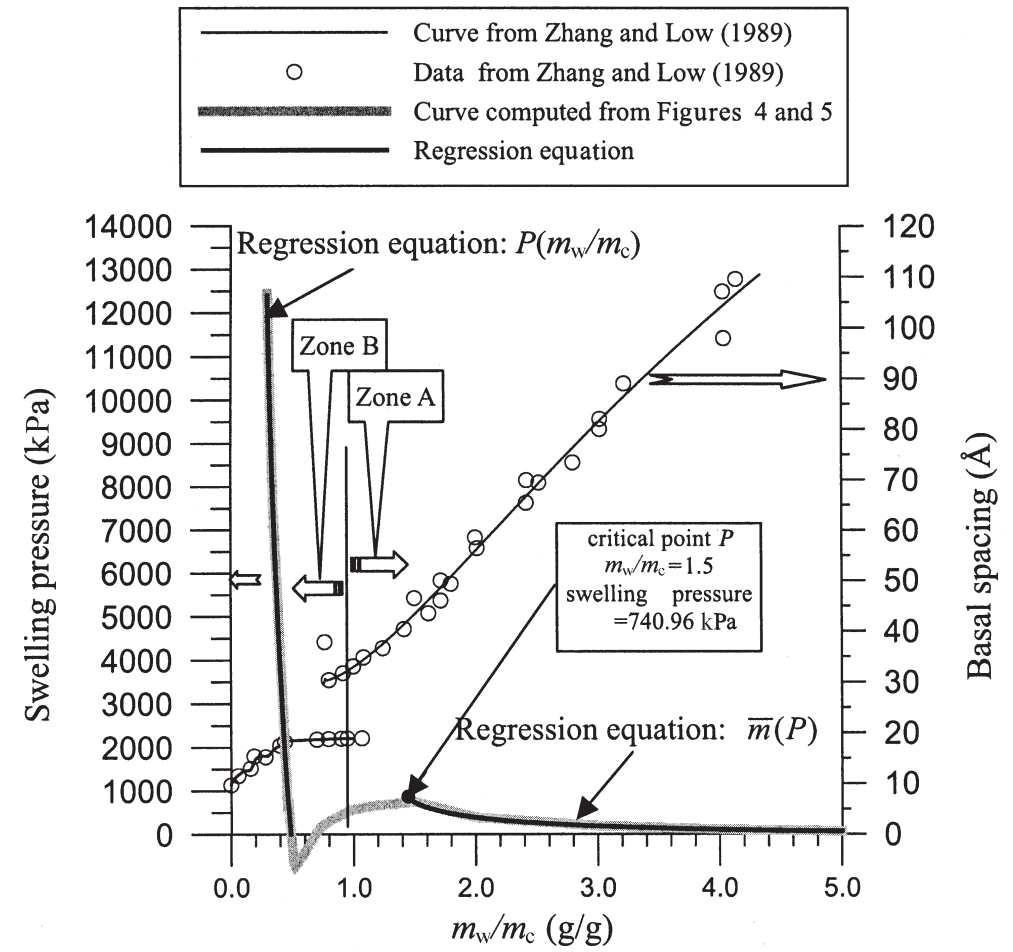

Figure 6. Relationships among swelling pressure, basal spacing and $m_{\mathrm{w}} / m_{\mathrm{c}}$ in a Na-smectite water system at $25^{\circ} \mathrm{C}$.

$$
\text { hs } \stackrel{\mathrm{K}}{\rightleftharpoons} \text { as }+n \mathrm{H}_{2} \mathrm{O}
$$

where hs denotes hydrous smectite; as denotes anhydrous smectite; $n$ is the number of moles of water released from 1 mole of hydrous smectite, and $\mathrm{K}=$
(4) thermodynamic equilibrium constant. Therefore, the reaction tends to move to the left when water content exceeds equilibrium (for example, before the end of primary consolidation), thereby generating a hydrous form of smectite with a higher volume than otherwise.

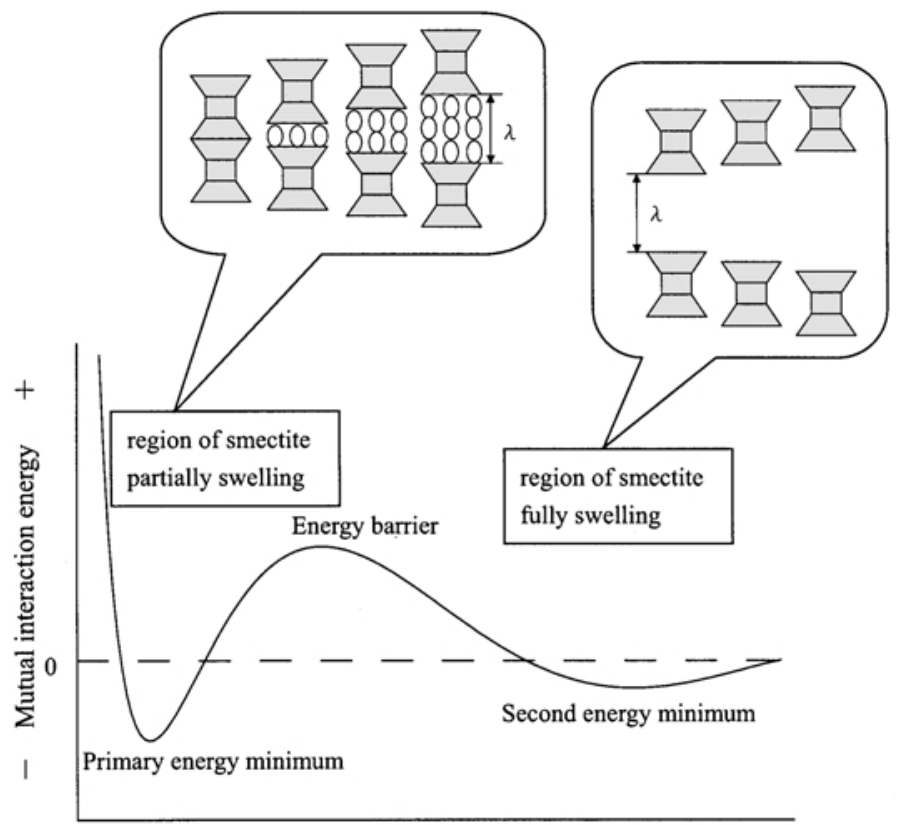

Interlayer distance, $\lambda$

Figure 7. Interaction energy vs. interlayer basal spacing of a hydrated smectite (after Zhang et al., 1995). 
After most of the pore water is slowly drained out, the reaction tends to move to the right until equilibrium is reached.

If the distribution of hydrous and anhydrous smectite is described as a mole fraction at equilibrium, then the thermodynamic equilibrium constant $(K)$ in equation 4 can be expressed as

$$
\mathrm{K}=\frac{a_{\mathrm{as}}\left(a_{\mathrm{H}_{2} \mathrm{O}}\right)^{n}}{a_{\mathrm{hs}}}=\frac{X_{\mathrm{as}} \lambda_{\mathrm{as}}\left(a_{\mathrm{H}_{2} \mathrm{O}}\right)^{n}}{X_{\mathrm{hs}} \lambda_{\mathrm{hs}}}
$$

where $a_{\mathrm{i}}, X_{\mathrm{i}}$, and $\lambda_{\mathrm{i}}$ represent the activity, mole fraction, and activity coefficient of component i, respectively. Assuming a binary system wherein only hydrous and anhydrous smectite components are present in solidsolution, the sum of the mole fractions of hydrous and anhydrous smectite components equals one

$$
X_{\mathrm{hs}}+X_{\mathrm{as}}=1
$$

Then, equation 4 can be rewritten as

$$
\log \mathrm{K}=\log \left[\frac{1-X_{\mathrm{hs}}}{X_{\mathrm{hs}}}\right]+\left[\frac{\lambda_{\mathrm{as}}}{\lambda_{\mathrm{hs}}}\right]+n \log a_{\mathrm{H}_{2} \mathrm{O}}
$$

where the ratio $\lambda_{\text {as }} / \lambda_{\text {hs }}$ was set to be constant by assuming that the effect of pressure on $\lambda_{\mathrm{as}} / \lambda_{\mathrm{hs}}$ is negligible.

Defining a parameter $\Phi$ as

$$
\Phi \equiv \log \left(\frac{1-X_{\mathrm{hs}}}{X_{\mathrm{hs}}}\right)+n \log a_{\mathrm{H}_{2} \mathrm{O}}
$$

a relationship between the equilibrium constant and $\Phi$ is established (Ransom and Helgeson, 1994a)

$$
\Phi=-W_{\mathrm{s}} / 2.30 \mathrm{R} T\left(2 X_{\mathrm{hs}}-1\right)+\log \mathrm{K}
$$

The value of $\Phi$ in equation 8 can be determined from the mole fraction of hydrous smectite, $X_{\mathrm{hs}}$. If the number of moles of water released per mole of hydrous smectite, $n$, is also known, a linear relationship between $\Phi$ ( $y$ axis) $v s$. $(2 X-1)(x$ axis $)$ can be plotted, yielding a slope of $-W_{\mathrm{s}} / 2.30 \mathrm{R} T$ and an intercept of $\log \mathrm{K}$.

Number of moles of water released per mole of hydrous smectite. The interlayer molar volume $\left(V_{\mathrm{il}}\right)$ can be determined by (Ransom and Helgeson, 1994a, 1994b)

$$
V_{\mathrm{il}}=\left(\frac{a b c \cdot \cos (90-\beta)}{10^{24} Z}\right) N_{0}
$$

where $a=5.17 \AA, b=8.99 \AA$ and $\beta=100^{\circ}$ are parameters associated with the smectite unit-cell; $c$ is the interlayer thickness; $Z=2$ is the number of units in the chemical formula of the smectite unit-cell, and $N_{0}$ is Avagadro's number.

Ransom and Helgeson (1994a) analyzed the XRD results of Power (1967), Burst (1969), Perry and Hower (1972) and Bruce (1984), and suggested that the basal spacing in a dioctahedral aluminous smectite structure ranges from 15.7 to $10 \AA$ in a subsurface hydrogeological environment. The $10 \AA$ basal spacing corresponds to free interlayer water of the dehydrated smectite, whereas the $15.7 \AA$ basal spacing represents the fully hydrated condition. If the basal spacing exceeds $15.7 \AA$, then the characteristics of the adsorbed water were proposed to resemble those of the bulk pore water. Although the experimentally measured basal spacing of the hydrated interlayer water may exceed $15.7 \AA$, Ransom and Helgeson (1994a) accepted the conclusion of van Olphen (1963), who suggested that the natural compaction of clay sediments could expel the water in the smectite interlayers and reduce the basal spacing to one equal to or smaller than $15.7 \AA$. Accordingly, they inferred that the basal spacing of smectite in the subsurface formation ranges from 15.7 to $10 \AA$ because an overburden of pressure can expel the adsorbed water the basal spacing of which exceeds $15.7 \AA$. Ransom and Helgeson (1994a) then derived a general formula that showed that 1 mole of a hydrated smectite mineral contains 4.5 moles of water, based on an interlayer basal spacing of 15.7 to $10 \AA$. Furthermore, they performed a regressional analysis of the data on relative humidity against the amount of interlayer water measured by Keren and Shainberg (1975) in Na-smectite at $25^{\circ} \mathrm{C}$ under 1 bar standard conditions, and developed a thermodynamic solid-solution model of smectite dehydration, including the equilibrium constant of the smectite dehydration reaction, the standard Gibbs freeenergy change and the mole fraction of hydrated and dehydrated smectite. Ransom and Helgeson (1995) extended the smectite dehydration model and derived the temperature and pressure-dependent equilibrium constant. However, the temperature and pressure-dependent equilibrium constant is yet to be validated by both field and laboratory experiments.

$\mathrm{Wu}$ et al. (1997) conducted a smectite hydration experiment at pressures from 1 to 8,555 bar and temperatures from 50 to $500^{\circ} \mathrm{C}$. The results are compared with those of the smectite dehydration solidsolution model developed by Ransom and Helgeson (1995) who suggested that the three layers of water molecules with a basal spacing of $\sim 19 \AA$ were thermodynamically valid and that the applicable basal spacing in the solid-solution model should be revised from $10 \AA$ associated with complete dehydration to $\sim 19 \AA$ associated with the fully hydrated end-member. Experimental results also imply that a pressure of $150 \mathrm{Mpa}$, equivalent to a depth of $6.5 \mathrm{~km}$ in the Gulf Basin, yields three interlayers of water molecules in $\mathrm{Ca}$ smectite. Fitts and Brown (1999) confirmed experimentally that the basal spacing in a hydrated Na-smectite at $25^{\circ} \mathrm{C}$ and at $1.3 \pm 0.3 \mathrm{Mpa}$ can fall from 18.5 to $15.4 \AA$ during dehydration (at an equivalent pressure to that at $60 \mathrm{~m}$ formation depth).

The discussion above shows that the thermodynamic solid-solution model developed by Ransom and Helgeson 
(1994a, 1995) needs to be modified and the basal spacing ranges extended from 10 to $19 \AA$, to describe completely the change in basal spacing during smectite dehydration. Hence, the land subsidence due to smectite dehydration caused by the over-pumping of groundwater can be quantified adequately. Substituting these values into equation 10 yields $V_{\mathrm{il}}=123.6 \mathrm{~cm}^{3} / \mathrm{mole}$. Based on the assumption of the structure of hydrous smectite, 1 mole of $\mathrm{O}_{10}(\mathrm{OH})_{2}$ and 0.3 mole of $\mathrm{Na}^{+}$are always present in 1 mole of hydrous smectite. The parameter $c$ is set to $9 \AA$ (19 ̊ minus $10 \AA$ ). Subtracting the molar volume of $\mathrm{Na}^{+}$ $\left(2.66 \mathrm{~cm}^{3}\right)$ from a hydrous smectite yields an interlayer water molar volume of $122.8 \mathrm{~cm}^{3} /$ mole. The number of moles of water released by the dehydration of hydrous smectite is thus

$$
n=\frac{\rho_{\mathrm{il}}}{M_{\mathrm{w}}} V_{\mathrm{il}}
$$

where $\rho_{\mathrm{il}}$ is the density of the interlayer water; $M_{\mathrm{w}}$ is the molecular weight of water and equals 18.05. Hawkins and Egelstaff (1980) measured the average interlayer water density as $1.05 \mathrm{~g} / \mathrm{cm}$. Substituting in values of $\rho_{\mathrm{il}}$ and $M_{\mathrm{w}}$, gives an $n$ value of 7.16.

Regression of experimental data. Fu et al. (1990) and Yasyerli et al. (1999) measured relative humidity $\left(P_{\mathrm{H}_{2} \mathrm{O}} /\right.$ $P_{\mathrm{H}_{2} \mathrm{O}}^{0}$ against $m_{\mathrm{w}} / m_{\mathrm{c}}$ in smectite-water and kaolinite-water systems, respectively, at $25^{\circ} \mathrm{C}$ and at 1 bar, as shown in Figure 8. These data are used to estimate the mole fraction of hydrous smectite in the solid-solution, $X_{\mathrm{hs}}$.

Smectite can adsorb water in the interlayer spacing and on the outer surface. Therefore, $\left(P_{\mathrm{H}_{2} \mathrm{O}} / P_{\mathrm{H}_{2} \mathrm{O}}^{0}\right.$ vs. $m_{\mathrm{w}} / m_{\mathrm{c}}$ as measured by Fu et al. (1990) must be modified. Ransom and Helgeson (1994a) showed that kaolinite does not have an interlayer spacing and a water molecule

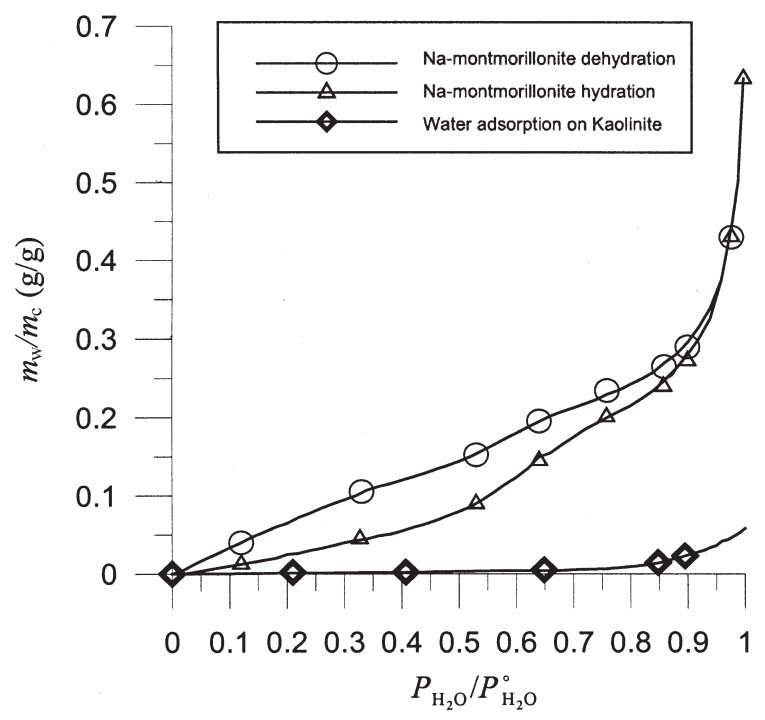

Figure 8. $\left(P_{\mathrm{H}_{2} \mathrm{O}} / P_{\mathrm{H}_{2} \mathrm{O}}^{0}\right)$ vs. $m_{\mathrm{w}} / m_{\mathrm{c}}$ for a Na-smectite-water system (after Fu et al., 1990; Yasyerli et al., 1999). can only be adsorbed at a surface position. Thereby, the data of Fu et al. (1990) for a smectite-water system and data measured by Yasyerli et al. (1999) for a kaolinitewater system can be used to derive the relationship of $\left(P_{\mathrm{H}_{2} \mathrm{O}} / P_{\mathrm{H}_{2} \mathrm{O}}^{0}\right)$ against $m_{\mathrm{w}} / m_{\mathrm{c}}$ and $X_{\mathrm{hs}}$ can be estimated.

A number of moles of water in the interlayer spacing of partially dehydrous smectite, $n_{\mathrm{il}}$, is given by

$$
n_{\mathrm{il}}=\frac{\left(g_{\mathrm{s}}-2 g_{\mathrm{k}}\right) M_{\mathrm{sm}}}{M_{w}}
$$

where $g_{\mathrm{s}}$ represents the mass of adsorbed water in smectite; $g_{\mathrm{k}}$ is the mass of adsorbed water in kaolinite, and $M_{\mathrm{sm}}$ is the molecular weight of smectite. The mole fraction of the hydrous smectite in a partially dehydrous state, $X_{\mathrm{hs}}$, is

$$
X_{\mathrm{hs}}=\frac{n_{\mathrm{il}}}{7.16}
$$

where 7.16 molecules of water are adsorbed in hydrous smectite.

Using the linear relationship of $\Phi v s .\left(2 X_{\mathrm{hs}}-1\right)$ defined in equation 8 and reconstructing the data in Figure 8 , yields Figure 9 . The slope, $-W_{\mathrm{s}} / 2.30 \mathrm{R} T$, in equation 9 is 2.30 , and the intercept, $\log \mathrm{K}$, is -1.76 . The activity of the adsorbed water in the hydrous smectite at ambient temperature and pressure is

$$
a_{\mathrm{H}_{2} \mathrm{O}} \cong\left(P_{\mathrm{H}_{2} \mathrm{O}} / P_{\mathrm{H}_{2} \mathrm{O}}^{0}\right)
$$

Figure 10 plots $a_{\mathrm{H}_{2} \mathrm{O}}$ against $X_{\mathrm{hs}}$ obtained from equations 12 to 14 . $X_{\mathrm{hs}}$ equals 0.79 , as the activity of water becomes unity.

Pressure dependent equilibrium constant. The thermodynamic solid-solution model of the smectite dehydra-

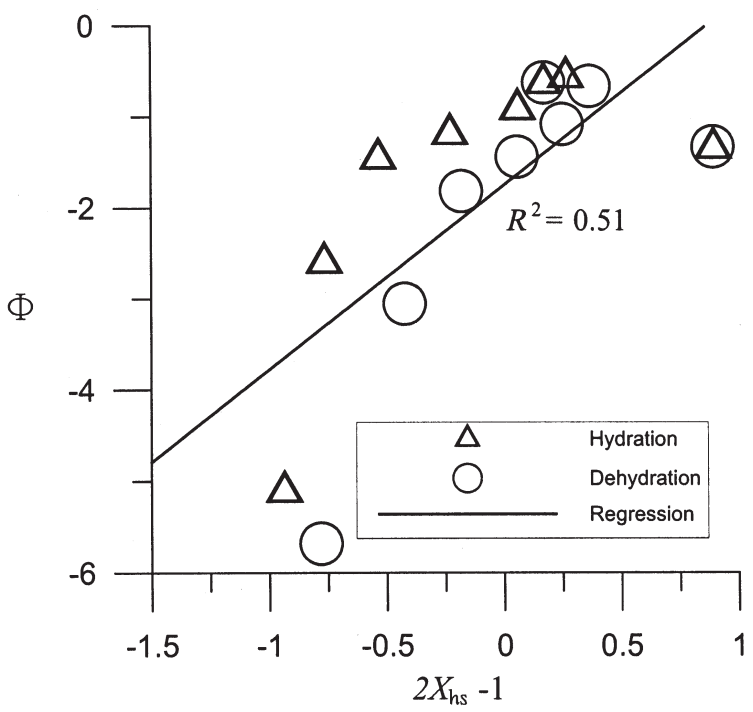

Figure 9. Using the linear relationship of $\Phi v s .\left(2 X_{\mathrm{hs}}-1\right)$ to obtain the slope $-W_{\mathrm{s}} / 2.30 \mathrm{R} T$ and intercept $(\log \mathrm{K})$. 
$\begin{array}{lllllllllll}0 & 0.1 & 0.2 & 0.3 & 0.4 & 0.5 & 0.6 & 0.7 & 0.8 & 0.9 & 1\end{array}$

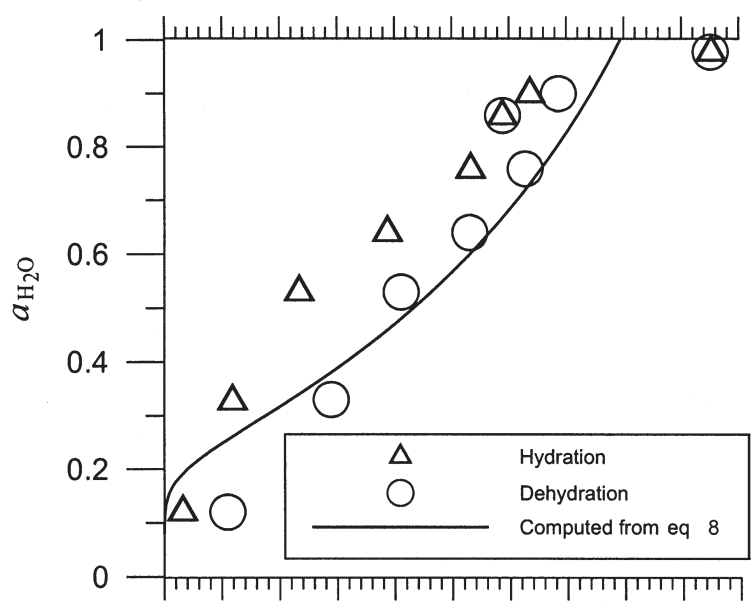

$\begin{array}{lllllllllll}0 & 0.1 & 0.2 & 0.3 & 0.4 & 0.5 & 0.6 & 0.7 & 0.8 & 0.9 & 1\end{array}$

\section{$X_{\text {hs }}$}

Figure 10. Interlayer water activity $\left(a_{\mathrm{H}_{2} \mathrm{O}}\right)$ vs. mole fraction of hydrous smectite $\left(X_{\mathrm{hs}}\right)$.

tion reaction is derived at $25^{\circ} \mathrm{C}$ and 1 bar. The basal spacing ranges from $10 \AA$ for complete dehydration to $19 \AA$ at complete hydration. However, the pressure in the subsurface shallow sediment exceeds 1 bar; thus, the change in the equilibrium constant at various pressures must be derived.

According to chemical equilibrium, $\log \mathrm{K}$ can be calculated from the change in Gibb's free energy $\left(G_{\mathrm{H}_{2} \mathrm{O}, P}\right)$ at any temperature and pressure, by the following equation.

$$
\log \mathrm{K}=-1 / 2.30 \mathrm{R} T\left(\Delta G_{\mathrm{r}}^{0}\right)
$$

where $\mathrm{R}$ and $T$ denote the gas constant $\left(8.31 \mathrm{~J} /\right.$ mole K$\left.^{-1}\right)$ and temperature $(\mathrm{K})$, respectively. $\Delta G_{\mathrm{r}}^{0}$ is the reaction Gibb's free energy and may change with the environmental conditions $(\mathrm{kcal} / \mathrm{mole})$. The relationship between pressure change and $\Delta G_{\mathrm{r}}^{0}$ at the reference temperature $(298.15 \mathrm{~K})$ is

$$
\Delta G_{\mathrm{r}, P}^{0}=\Delta G_{\mathrm{r}, P_{\mathrm{r}}}^{0}+\int_{P_{\mathrm{r}}}^{P} \Delta V d P
$$

where $P_{\mathrm{r}}$ is the reference pressure of $1 \mathrm{bar},(1 \mathrm{bar}=$ $100 \mathrm{kPa})$, and $P$ stands for any pressure of interest $(\mathrm{kPa})$. $\Delta V$ is the volume change due to the release (or swelling) of water from 1 mole of soil particles when the pressure changes from $P_{\mathrm{r}}$ to $P$, and can be expressed as

$$
\begin{aligned}
& \Delta V=\left(V_{\mathrm{hs}, P}^{0}-V_{\mathrm{hs}, P_{\mathrm{r}}}^{0}\right)+\left(V_{\mathrm{as}, P}^{0}-V_{\mathrm{as}, P_{\mathrm{r}}}^{0}\right)+ \\
& 7.16\left(V_{\mathrm{H}_{2} \mathrm{O}, P}^{0}-V_{\mathrm{H}_{2} \mathrm{O}, P_{\mathrm{r}}}^{0}\right)
\end{aligned}
$$

where $\left(V_{\mathrm{hs}, P}^{0}-V_{\mathrm{hs}, P_{\mathrm{r}}}^{0}\right)$ denotes the change in the molar volume of hydrous smectite as the pressure changes from $P_{\mathrm{r}}$ to $P\left(\mathrm{~cm}^{3} /\right.$ mole $) ;\left(V_{\mathrm{as}, P}^{0}-V_{\mathrm{as}, P_{\mathrm{r}}}^{0}\right)$ denotes the change in the molar volume of anhydrous smectite as the pressure changes from $P_{\mathrm{r}}$ to $P\left(\mathrm{~cm}^{3} / \mathrm{mole}\right)$, and $\left(V_{\mathrm{H}_{2} \mathrm{O}, P}^{0}-V_{\mathrm{H}_{2} \mathrm{O}, P_{\mathrm{r}}}^{0}\right)$ denotes the change in molar volume of water when the pressure changes from $P_{\mathrm{r}}$ to $P\left(\mathrm{~cm}^{3} / \mathrm{mole}\right)$.

The experimental data in Figure 6, for which the swelling pressure $>1$ bar are selected then, a regression of $m_{\mathrm{w}} / m_{\mathrm{c}} v s$. swelling pressure in the smectite water system, yields

$$
\begin{aligned}
& P\left(m_{\mathrm{w}} / m_{\mathrm{c}}\right)= \\
& \frac{a_{2}+c_{2}\left(\frac{m_{\mathrm{w}}}{m_{\mathrm{c}}}\right)^{2}+e_{2}\left(\frac{m_{\mathrm{w}}}{m_{\mathrm{c}}}\right)^{4}+g_{2}\left(\frac{m_{\mathrm{w}}}{m_{\mathrm{c}}}\right)^{6}+i_{2}\left(\frac{m_{\mathrm{w}}}{m_{\mathrm{c}}}\right)^{8}}{1+b_{2}\left(\frac{m_{\mathrm{w}}}{m_{\mathrm{c}}}\right)^{2}+d_{2}\left(\frac{m_{\mathrm{w}}}{m_{\mathrm{c}}}\right)^{4}+f_{2}\left(\frac{m_{\mathrm{w}}}{m_{\mathrm{c}}}\right)^{6}+h_{2}\left(\frac{m_{\mathrm{w}}}{m_{\mathrm{c}}}\right)^{8}+j_{2}\left(\frac{m_{\mathrm{w}}}{m_{\mathrm{c}}}\right)^{10}}
\end{aligned}
$$

where $a_{2}=281205.92, b_{2}=144.55, c_{2}=-3053451.86$, $d_{2}=-1024.38, e_{2}=12393272.52, f_{2}=2493.08, g_{2}=$ $-22966605.92, h_{2}=-3372.84, i_{2}=16427912.70, j_{2}=$ 6996.25 .

The value of $P\left(m_{\mathrm{w}} / m_{\mathrm{c}}\right)$ obtained from equation 18 and the relationship of $m_{\mathrm{w}} / m_{\mathrm{c}}$ with the basal spacing (c) yields the relationship between basal spacing and swelling pressure as

$$
\begin{aligned}
c(P)= & a_{3}+b_{3} P+c_{3} P^{2}+d_{3} P^{3}+e_{3} P^{4}+f_{3} P^{5}+ \\
& g_{3} P^{6}+h_{3} P^{7}+i_{3} P^{8}+j_{3} P^{9}+k_{3} P^{10}+l_{3} P^{11}+ \\
& m_{3} P^{12}+n_{3} P^{13}+o_{3} P^{14}+p_{3} P^{15}+q_{3} P^{16}
\end{aligned}
$$

where $a_{3}=18.42, b_{3}=9.76 \times 10^{-5}, c_{3}=-1.13 \times 10^{-7}$, $d_{3}=1.33 \times 10^{-11}, e_{3}=-7.57 \times 10^{-16}, f_{3}=2.56 \times 10^{-20}$, $g_{3}=-5.68 \times 10^{-25}, \quad h_{3}=8.81 \times 10^{-30}, \quad i_{3}=$ $-9.86 \times 10^{-35}, j_{3}=8.12 \times 10^{-40}, k_{3}=-4.96 \times 10^{-45}$, $l_{3}=2.24 \times 10^{-50}, m_{3}=-7.40 \times 10^{-56}, n_{3}=1.73 \times 10^{-61}$, $o_{3}=-2.73 \times 10^{-67}, \quad p_{3}=2.59 \times 10^{-73}, \quad q_{3}=$ $-1.12 \times 10^{-79}$.

Substituting equation 19 into equation 10 to obtain the molar volume of hydrous smectite enables the $\int_{P_{\mathrm{r}}}^{P} \Delta V$ $d P$ part in equation 16 to be expressed as

$$
\int_{P_{\mathrm{r}}}^{P} \Delta V d P=
$$

$\int_{P_{\mathrm{r}}}^{P}\left\{13.73\left[c(P)-c\left(P_{\mathrm{r}}\right)\right]+7.16\left(V_{\mathrm{H}_{2} \mathrm{O}, P}^{0}-V_{\mathrm{H}_{2} \mathrm{O}, P_{\mathrm{r}}}^{0}\right)\right\} d P=$ $13.73 \int_{P_{\mathrm{r}}}^{P}\left[c(P)-c\left(P_{\mathrm{r}}\right)\right] d P+7.16\left(G_{\mathrm{H}_{2} \mathrm{O}, P}^{0}-G_{\mathrm{H}_{2} \mathrm{O}, P_{\mathrm{r}}}^{0}\right)-$

$7.16_{\mathrm{H}_{2} \mathrm{O}, P_{\mathrm{r}}}^{0}\left(P-P_{\mathrm{r}}\right)$

where $c\left(P_{P}\right)$ is the basal spacing at the reference pressure $\left(P_{\mathrm{r}}\right) ; G_{\mathrm{H}_{2} \mathrm{O}, P}^{0}$ and $G_{\mathrm{H}_{2} \mathrm{O}, P_{\mathrm{r}}}^{0}$ denote the standard molar Gibbs free energy of bulk water at pressures $P$ and $P_{\mathrm{r}}$, respectively. The values of $\left(G_{\mathrm{H}_{2} \mathrm{O}, P}^{0}-G_{\mathrm{H}_{2} \mathrm{O}, P_{\mathrm{r}}}^{0}\right)$ and $V_{\mathrm{H}_{2} \mathrm{O}, P}^{0}$ in this study were generated using the computer program SUPCRT92 (Johnson et al., 1992). Thereby, equations 17 and 20 can be used to compute the standard molar Gibbs free energy at a specific formation pressure; then equation 15 can be employed to determine the 
corresponding equilibrium constant K. Finally, equation 7 can be adopted to determine the mole fractions of hydrous and anhydrous smectite, $X_{\mathrm{hs}, P}$ and $X_{\mathrm{as}, P}$ respectively, at a formation pressure, $P$.

\section{ESTIMATION PROCEDURES}

Consider the equilibrium condition in which swelling pressure balances the effective stress (Figure 11). Recall Figure 6 , as $m_{\mathrm{w}} / m_{\mathrm{c}}$ decreases from $\sim 5$ to $\sim 1.5 \mathrm{~g} / \mathrm{g}$, the corresponding swelling pressure increases from $64.94 \mathrm{kPa}(\sim 6 \mathrm{~m}$ below the surface) to $740.95 \mathrm{kPa}$ ( $\sim 66 \mathrm{~m}$ depth below the surface) and then reaches a critical value $P$. If $m_{\mathrm{w}} / m_{\mathrm{c}}$ declines further from $\sim 1.5 \mathrm{~g} / \mathrm{g}$, then the swelling pressure will drop rapidly even to negative values, triggering a discontinuous jump in the basal spacing. Thus, the pumping of groundwater results in a drawdown of groundwater and decreases the pressure of the pore water. The effective stress applied to the hydrous smectite increases correspondingly. Based on Figure 6, three different conditions may pertain.

Condition 1. The original effective stress applied to the smectite is $<740.95 \mathrm{kPa}$. As the groundwater is pumped, the effective stress increases but remains $<740.95 \mathrm{kPa}$. This condition is said to pertain Zone A, to the right hand of the critical point $\mathrm{P}$ (Figure 6). In Zone A, the swelling pressure increases as $m_{\mathrm{w}} / m_{\mathrm{c}}$ decreases and the basal spacing decreases accordingly.

Condition 2. The original effective stress applied to the smectite is $<740.95 \mathrm{kPa}$. As the groundwater is pumped, the effective stress increases and exceeds $740.95 \mathrm{kPa}$. The condition depicted in Figure 6 reveals the original effective stress in Zone A, to the right of the critical point $P$, increases past the critical point $P$ of a discontinuous jump in the basal spacing, and enters into Zone B. The basal spacing is reduced from its value under stable conditions to $\sim 19 \AA\left(m_{\mathrm{w}} / m_{\mathrm{c}}\right.$ decreases to $1.0 \mathrm{~g} / \mathrm{g}$ ) and the dehydration reaction continues until it reaches chemical equilibrium.

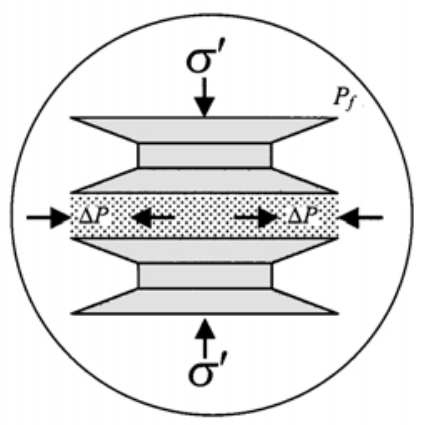

$\sigma:$ total stress

$\sigma^{\prime}:$ effective stress

$P_{\mathrm{f}}:$ pore pressure

$\Delta P:$ swelling pressure

Figure 11. Schematic diagram of the equilibrium between swelling pressure and effective stress in the interlayer of $\mathrm{Na}-$ smectite (after Fitts and Brown, 1999).
Condition 3. The original effective stress applied to the smectite exceeds $740.95 \mathrm{kPa}$, i.e. the smectite has to pass through the region of a discontinuous jump in the basal spacing and is in Zone $\mathrm{B}$. The dehydration reaction is at chemical equilibrium. As the pumping begins, the increase in effective stress disturbs the dehydration reaction and leads to the dehydration reaction.

Given the above three dehydration conditions, two methods for evaluating the effect of smectite dehydration on land subsidence due to the over pumping of groundwater are presented.

\section{Subsidence due to the hydration state of the interlayer}

Consider that the smectite is initially subjected to an effective stress of $<740.95 \mathrm{kPa}$. The amount of subsidence of hydrous smectite is estimated from its interlayer's hydration state. Brown and Ransom (1996) and Fitts and Brown (1999) proposed a modified equation for porosity $(\phi)$ based on the hydration state of smectite. The porosity of soil is defined as

$$
\phi \equiv \frac{V_{\mathrm{v}}}{V_{\mathrm{T}}}=\left(\frac{M_{\mathrm{p}}}{\rho_{\mathrm{w}}}\right) /\left(\frac{1}{\rho_{\mathrm{b}}}\right)=\left(\frac{W_{\mathrm{c}} M_{\mathrm{s}}}{\rho_{\mathrm{w}}}\right) \rho_{\mathrm{b}}
$$

where $\phi$ : porosity, $V_{\mathrm{v}}$ : void volume of soil $\left(\mathrm{cm}^{3}\right), V_{\mathrm{T}}$ : bulk volume of soil $\left(\mathrm{cm}^{3}\right), M_{\mathrm{p}}$ : mass of water released by heating per unit mass of soil $(\mathrm{g}), M_{\mathrm{s}}$ : mass of dry soil after dewatering by heating per unit mass of soil $(\mathrm{g}), W_{\mathrm{c}}$ : ratio of pore-water mass to dry soil mass, $\rho_{\mathrm{w}}$ : pore water density $\left(\mathrm{g} / \mathrm{cm}^{3}\right), \rho_{\mathrm{b}}$ : soil bulk density $\left(\mathrm{g} / \mathrm{cm}^{3}\right)$.

Additionally, $M_{\mathrm{p}}+M_{\mathrm{s}}=1$, and $W_{\mathrm{c}}=M_{\mathrm{p}} / M_{\mathrm{s}}$ leads to

$$
M_{\mathrm{s}}=\frac{1}{1+W_{\mathrm{c}}}
$$

Therefore, the modified porosity equation of hydrous smectite can be regressed as (Brown and Ransom, 1996)

$$
\phi_{\alpha}=\frac{\rho_{\mathrm{b}}\left(\frac{\phi \rho_{\mathrm{w}}}{M_{\mathrm{s}} \rho_{\mathrm{b}}}-\frac{A \alpha}{1-\alpha}\right)}{\rho_{\mathrm{w}}\left(1+\frac{\phi \rho_{\mathrm{w}}}{M_{\mathrm{w}} \rho_{\mathrm{b}}}\right)}
$$

Regressing the equation for $m_{\mathrm{w}} / m_{\mathrm{c}}$ the swelling pressure $(P)$ for $m_{\mathrm{w}} / m_{\mathrm{c}}$ from $\sim 5$ to $\sim 1.5 \mathrm{~g} / \mathrm{g}$ in Figure 6 yields

$$
\begin{array}{r}
\bar{m}(P)=a_{4}+b_{4} / \ln P+c_{4} /(\ln P)^{2}+d_{4} /(\ln P)^{3}+ \\
e_{4} /(\ln P)^{4}+f_{4} /(\ln P)^{5}
\end{array}
$$

where $a_{4}=42.29, b_{4}=-813.70, c_{4}=5538.86, d_{4}=$ $-14365.26, e_{4}=7932.78, f_{4}=14162.76$

$$
\alpha=\bar{m}(P) /(1+\bar{m}(P))
$$

The value of $\alpha$ at different swelling pressures (or effective stress) can be determined using equation 24 , and substituted in equation 23 to yield the modified porosity of smectite in the hydrous state. The physical interpretations of soil porosity $(\phi)$ and modified porosity of smectite in the hydrous state at $\alpha_{1}$ and $\alpha_{2}$ (where $\alpha_{1}>$ $\alpha_{2}, \phi>\phi_{\alpha_{2}}>\phi_{\alpha_{1}}$ ) are as follows. 
The term $\phi$ is measured by vaporizing the interlayer water and thus overestimates the soil void volume and yields the largest porosity; a higher hydrous state of smectite refers to the occupancy of interlayer water of more void volume and a smaller porosity, and vice versa. Thus, the difference between the porosity in the hydrous states $\alpha_{1}$ and $\alpha_{2}$ of smectite is

$$
\Delta \phi=\phi_{\alpha_{2}}-\phi_{\alpha_{1}}
$$

Initially, the aquifer is not over pumped; the original hydrous state of smectite is at $\alpha_{1}$. As the aquifer is over pumped, the effective stress and the swelling pressure increase accordingly to compact the soil skeleton and expel water from the interlayer. The hydrous state of smectite is then $\alpha_{2}$. The volume of water expelled from the interlayers of smectite in hydrous states $\alpha_{1}$ and $\alpha_{2}$ is $\Delta \phi \cdot V_{\mathrm{T}}$ and equals the compressed volume of smectite. Accordingly, the amount of subsidence caused by the expulsion of interlayer water from smectite is

$$
H_{1}=\Delta \phi \times d_{\mathrm{c}}
$$

where $H_{1}$ is the subsidence due to the change in hydrous state $(\mathrm{cm})$ and $d_{\mathrm{c}}$ is the original formation thickness (cm).

\section{Subsidence due to interlayer dehydration}

If the smectite has undergone effective stress $>740.95 \mathrm{kPa}$, the solid-solution model can be used to determine land subsidence due to interlayer dehydration. Modify equation 16 as

$$
\Delta G_{\mathrm{r}, P_{\mathrm{p}}}^{0}=\Delta G_{\mathrm{r}, P}^{0}+\int_{P}^{P_{\mathrm{p}}} \Delta V d P
$$

where $P_{\mathrm{P}}$ : applied effective stress (or swelling pressure) on smectite after pumping $(\mathrm{kPa}) ; P$ : initially applied effective stress (or swelling pressure) on smectite before pumping $(\mathrm{kPa}) ; \Delta V$ : volume change caused by pressure change from $P$ to $P_{\mathrm{P}}\left(\mathrm{cm}^{3} / \mathrm{mole}\right) ; \Delta G_{\mathrm{r}, P_{\mathrm{p}}}^{0}$ : reaction Gibb's free energy at $P_{\mathrm{P}}(\mathrm{Kcal} / \mathrm{mole})$; and $\Delta G_{\mathrm{r}, P}^{0}$ : reaction Gibb's free energy at $P$ (kcal/mole).

From equation 14, the volume change due to a pressure change from $P$ to $P_{\mathrm{P}}$ is

$$
\begin{aligned}
\Delta V=\left(V_{\mathrm{hs}, P_{\mathrm{p}}}^{0}-V_{\mathrm{hs}, P}^{0}\right)+( & \left.V_{\mathrm{as}, P_{\mathrm{p}}}^{0}-V_{\mathrm{as}, P}^{0}\right)+ \\
& 7.16\left(V_{\mathrm{H}_{2} \mathrm{O}, P_{\mathrm{p}}}^{0}-V_{\mathrm{H}_{2} \mathrm{O}, P}^{0}\right)
\end{aligned}
$$

where $\left(V_{\mathrm{hs}, P_{\mathrm{p}}}^{0}-V_{\mathrm{hs}, P}^{0}\right)$ : volume changes per mole of hydrous smectite as pressure changes from $P$ to $P_{\mathrm{P}}\left(\mathrm{cm}^{3} /\right.$ mole); $\left(V_{\mathrm{as}, P_{\mathrm{p}}}^{0}-V_{\mathrm{as}, P}^{0}\right)$ : volume changes in anhydrous smectite as pressure changes from $P$ to $P_{\mathrm{P}}\left(\mathrm{cm}^{3} / \mathrm{mole}\right)$; $\left(V_{\mathrm{H}_{2} \mathrm{O}, P_{\mathrm{p}}}^{0}-V_{\mathrm{H}_{2} \mathrm{O}, P}^{0}\right)$ : volume changes per mole of water as pressure changes from $P$ to $P_{\mathrm{P}}\left(\mathrm{cm}^{3} /\right.$ mole $)$.

Thereby, the second term on the right-hand side of equation 28 can be expressed as

$$
\begin{aligned}
& \int_{P}^{P_{\mathrm{p}}} \Delta V d P= \\
& \int_{P}^{P_{\mathrm{p}}}\left\{13.73\left[c\left(P_{\mathrm{p}}\right)-c(P)\right]+7.16\left(V_{\mathrm{H}_{2} \mathrm{O}, P_{\mathrm{P}}}^{0}-V_{\mathrm{H}_{2} \mathrm{O}, P}^{0}\right)\right\} d P= \\
& 13.73 \int_{P}^{P_{\mathrm{p}}} c(P) d P-13.73 c(P)\left(P_{\mathrm{P}}-P\right)+ \\
& 7.16\left(G_{\mathrm{H}_{2} \mathrm{O}, P_{\mathrm{p}}}^{0}-G_{\mathrm{H}_{2} \mathrm{O}, P}^{0}\right)-7.16 V_{\mathrm{H}_{2} \mathrm{O}, P}^{0}\left(P_{\mathrm{p}}-P\right)
\end{aligned}
$$

where $c(P)$ denotes the basal spacing $(\AA)$ at pressure $P$.

Equations 28-30 can be used to evaluate the standard Gibb's free energy of an increase in effective stress $\left(P_{\mathrm{P}}\right)$ caused by the over pumping of groundwater. The corresponding equilibrium constant $\mathrm{K}$ can be computed using equation 15. Equation 7 then determines the hydrous and anhydrous mole fractions of smectite at $P_{\mathrm{P}}\left(X_{\mathrm{hs}, P_{\mathrm{P}}}\right.$ and $X_{\mathrm{as}, P_{\mathrm{P}}}$, respectively). The mole fraction change due to smectite dehydration from $P$ to $P_{\mathrm{P}}$ is

$$
\Delta X_{\mathrm{as}}=X_{\mathrm{as}, P}-X_{\mathrm{as}, P_{\mathrm{p}}}
$$

Thus, the land subsidence caused by over pumping required to trigger the dehydration of smectite is

$$
H_{2}=\frac{\Delta X_{\mathrm{as}} \times V_{\mathrm{cw}} \times d_{\mathrm{c}} \times P_{\mathrm{s}}}{V_{\mathrm{c}}}
$$

where $\mathrm{H}_{2}$ : amount of land subsidence estimated using the theory of the interlayer dehydration of solid-solution $(\mathrm{cm})$; $V_{\mathrm{cw}}$ : water volume per mole of smectite $\left(122.8 \mathrm{~cm}^{3} / \mathrm{mol}\right) ; d_{\mathrm{c}}$ : original thickness of formation $(\mathrm{cm}) ; P_{\mathrm{s}}$ : proportion of smectite in a clay system; $X_{\mathrm{as}}$ : mole fraction of anhydrous smectite due to dehydration of smectite; and $V_{\mathrm{c}}$ : molar volume of anhydrous smectite. This study adopts Montana II $\left(\mathrm{Na}_{0.76}\left(\mathrm{Al}_{1.51}\right.\right.$ $\left.\mathrm{Mg}_{0.19} \mathrm{Fe}_{0.23}^{3+}\right)\left(\mathrm{Al}_{0.34} \mathrm{Si}_{3.66}\right) \mathrm{O}_{10}(\mathrm{OH})_{2} \cdot 4.5 \mathrm{H}_{2} \mathrm{O}$, of which the molar volume is $215.36 \mathrm{~cm}^{3} / \mathrm{mol}$ (Ransom and Helgeson, 1994b); changes the amount of interlayer water from 4.5 to 7.16 mole and modifies $V_{\mathrm{c}}=$ $\left.260.67 \mathrm{~cm}^{3} / \mathrm{mol}\right)$.

The overall subsidence $(H)$ caused by the dehydration following the over pumping of groundwater is the summation of the subsidence due to the change in interlayer hydration state $\left(H_{1}\right)$ and the subsidence due to interlayer dehydration $\left(H_{2}\right)$

$$
H=H_{1}+H_{2}
$$

\section{FIELD APPLICATIONS}

The Yun Lin coastal area, located in the southwestern coastal region of Taiwan, is in the southern part of the Chuo-Shui River alluvial fan as depicted in Figure 12. The Taiwanese government has targeted the Tai-Shi and Mai-Liao area, located along the Yun Lin coastal line, as 


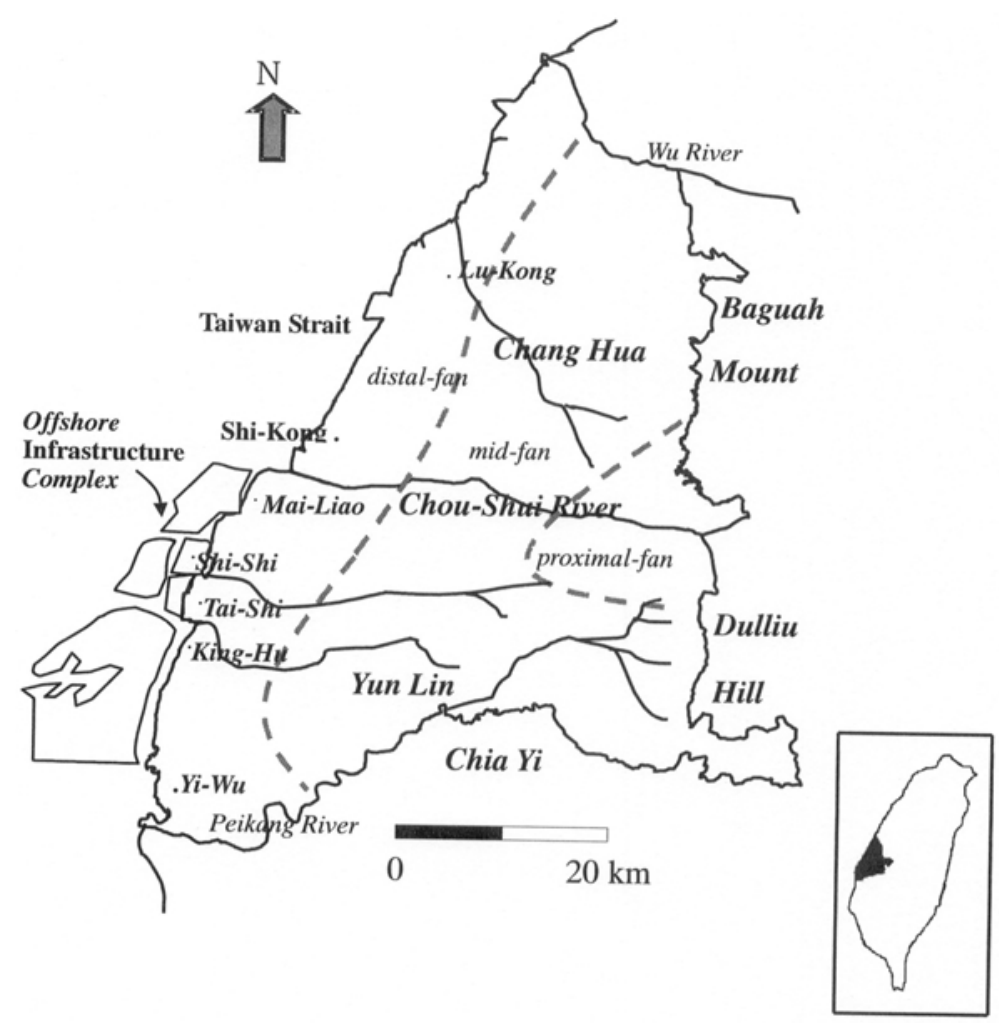

Figure 12. Location of Chou-Shui River alluvial fan in Taiwan.

a major industrial infrastructure complex and intends to construct a high-speed railroad route in the near future. Subsidence-monitoring data shows the Yun Lin coastal area is still subsiding. Therefore, the evaluation of the cumulative amount of land subsidence in this area is critical. The alluvial fan has an area of $\sim 1800 \mathrm{~km}^{2}$ and is broadly partitioned into the proximal-fan, mid-fan and distal-fan areas. Unconsolidated sediments that underlie the alluvial fan contain much groundwater and are of late Quaternary age. The hydrogeological proximal-fan formation, which is primarily composed of gravel and sand, is regarded as an unconfined aquifer. The aquitards in the distal-fan and mid-fan areas gradually diminish toward the east. The conceptual hydrogeological profile suggests that highly permeable materials are assumed to be present in the extended aquitards of the proximal-fan area. The upper aquifer is then labeled 'aquifer 1'. The intermediate aquifer is labeled 'aquifer 2'. Finally, the lower aquifer is labeled 'aquifer 3' (Figure 13). The long-term average amounts of groundwater pumped and recharged from 1970 to 1990 were 1.326 and $1.024 \times 10^{9} \mathrm{~m}^{3} / \mathrm{y}$, respectively. These statistics indicate that a substantial amount of groundwater was overdrafted from the aquifers (Central Geological Survey, 1999). Groundwater levels fell markedly from 1970 to 1990 but recovered slightly after 1991 .

Subsidence at Yun Lin began in 1970. Before 1980, the region of subsidence was limited within the King-Hu area. In 1980, the region of land subsidence extended to the Tai-Shi area and in 1987 the land subsidence further expanded to the estuary of the Chou-Shui River. By 1998, the annual subsidence exceeded $10 \mathrm{~cm} / \mathrm{y}$ in the Yun Lin coastal area of $\sim 120 \mathrm{~km}^{2}$. The cumulative land subsidences from 1975 to 2000 at Mai-Liao, King-Hu, Tai-Shi and Yi-Wu were 92, 195, 208 and $188 \mathrm{~cm}$, respectively (Water Resources Bureau, 2001a). Tai-Shi is the most seriously affected area. The model developed is thus used to examine the effect of smectite dehydration on land subsidence in the Yun Lin offshore industrial infrastructure complex and the Tai-Shi area.

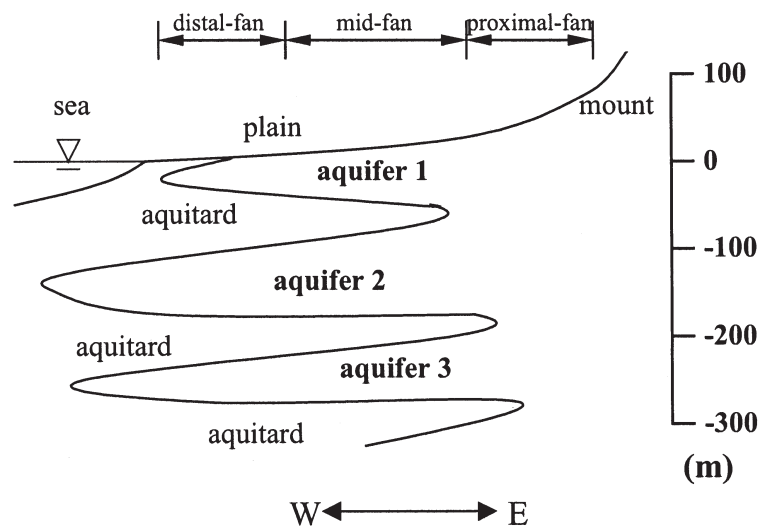

Figure 13. Conceptual hydrogeological profile of Chou-Shui River alluvial fan. 


\section{Yun Lin offshore industrial infrastructure complex}

The Yun Lin offshore industrial infrastructure complex is to be developed by pumping ocean sand to construct offshore land for industrial needs (Figure 12). The Industry Bureau has estimated that the surface subsidence of the new land was $60-70 \mathrm{~cm}$ in the first year, $<10 \mathrm{~cm}$ in the fourth year and will stabilize to a negligible value after the fifth year. The analysis by the Industry Bureau did not account for the effect of smectite dehydration on the subsidence of the land (Industry Bureau, 2000). Given the stratigraphic core sequence and the soil's mechanical properties recorded at the land subsidence monitoring well in the Shi-Shi district, Terzaghi's (1925) one-dimensional compaction theory is employed to compute the land subsidence caused by primary consolidation in a layered formation and that caused by smectite dehydration.

Table 2 presents computed results obtained using Terzaghi's one-dimensional compaction theory; the final cumulative subsidence of a $200 \mathrm{~m}$-thick offshore formation is predicted to be $69.64 \mathrm{~cm}$. The amount of subsidence will be $61.15 \mathrm{~cm}$ over a compacting time of 285.5 days, comprising $95 \%$ of the final accumulative subsidence. The subsidence becomes $69.40 \mathrm{~cm}$ after 900 days (or $2.5 \mathrm{y}$ ) of compaction, and then reaches its final value. Figure 14 is a plot of the measured land subsidence and the computed land subsidence, according to Terzaghi's compaction theory, against time for a $200 \mathrm{~m}$ deep formation. The measured land subsidence does not stabilize after the fifth year whereas the computed land subsidence stabilizes after $\sim 2.5 \mathrm{y}$. The difference between the measured and computed stable land subsidence is $32.75 \mathrm{~cm}$. Using the smectite dehydration model, the computed land subsidence caused by smectite dehydration is $30.07 \mathrm{~cm}$ including $29.65 \mathrm{~cm}$ of $H_{1}$ and $0.42 \mathrm{~cm}$ of $H_{2}$ as shown in Table 3, which is close to the underestimate of $32.75 \mathrm{~cm}$,

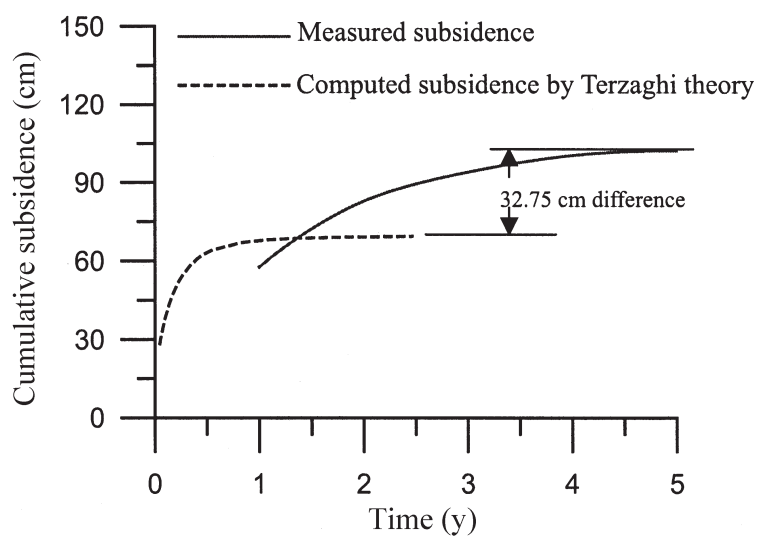

Figure 14. Comparison of the measured land subsidence and land subsidence computed using Terzaghi theory at a depth of $0-200 \mathrm{~m}$ in the Yun Lin offshore industrial infrastructure complex. obtained using Terzaghi compaction theory. Including the effect of smectite dehydration on subsidence yields a computed result that agrees well with the measured subsidence data.

\section{Tai-Shi area}

Tai-Shi is located in the Yun Lin coastal area (Figure 12). The original groundwater level of Tai-Shi before land subsidence was $0 \mathrm{~m}$ in 1968 . By 2000, the multilevel monitoring well observed groundwater levels of $-8,-17.2,-17.2$ and $-10 \mathrm{~m}$, respectively, at depths 49, 105, 203 and $282 \mathrm{~m}$ (Water Resources Bureau, 2001b). The fall in groundwater level was used to compute the increase in effective stress in the strata. Based on the stratigraphic core sequence obtained from the land subsidence monitoring well in Tai-Shi, the strata are divided into 58 parts and grouped in 33 sublayers by classification as clay, clay/fine sand, sand and gravel (Figure 15).

The subsidence determined from smectite dehydration caused by the over pumping of groundwater in TaiShi (depth of $300 \mathrm{~m}$ ) is $19.88 \mathrm{~cm}$ including $19.77 \mathrm{~cm}$ of $H_{1}$ and $0.108 \mathrm{~cm}$ of $H_{2}$. The amount of subsidence resulting from the solid-solution model of smectite dehydration, when the effective stress applied to the strata exceeds $740.95 \mathrm{kPa}$ after over pumping in Tai-Shi, is $0.108 \mathrm{~cm}\left(\mathrm{H}_{2}\right)$, representing only $0.54 \%$ of overall subsidence caused by smectite dehydration.

Figure 15 is a plot of measured accumulated subsidence and computed land subsidence from smectite dehydration, against depth in Tai-Shi. The results indicate that the major land subsidence caused by smectite dehydration occurs in shallow subsurface formations ( $\sim$ to $60 \mathrm{~m}$ depth) whereas only a small amount of land subsidence caused by smectite dehydration was present at a depth of $>60 \mathrm{~m}$. The increase in the effective stress caused by the fall in groundwater level is

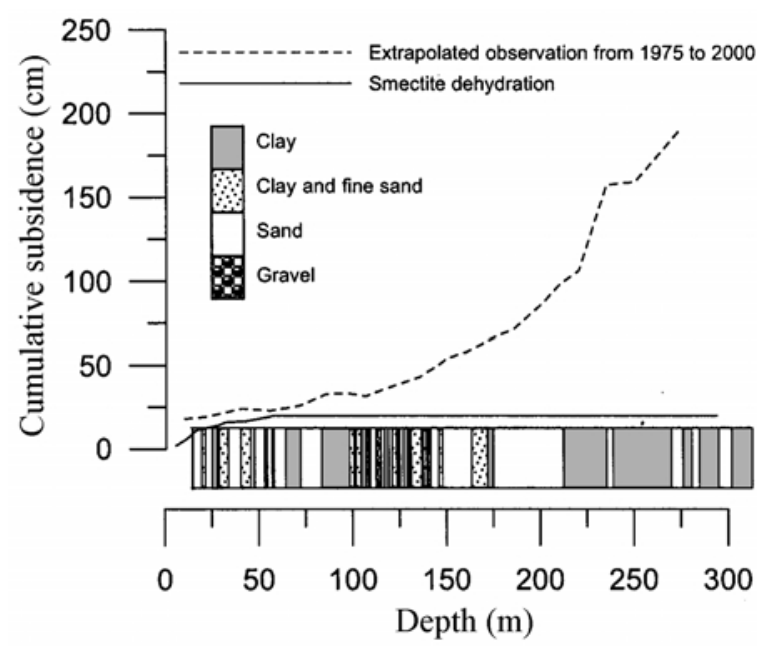

Figure 15. Comparison of the cumulative measured land subsidence and land subsidence caused by smectite dehydration vs. depth in Tai-Shi. 


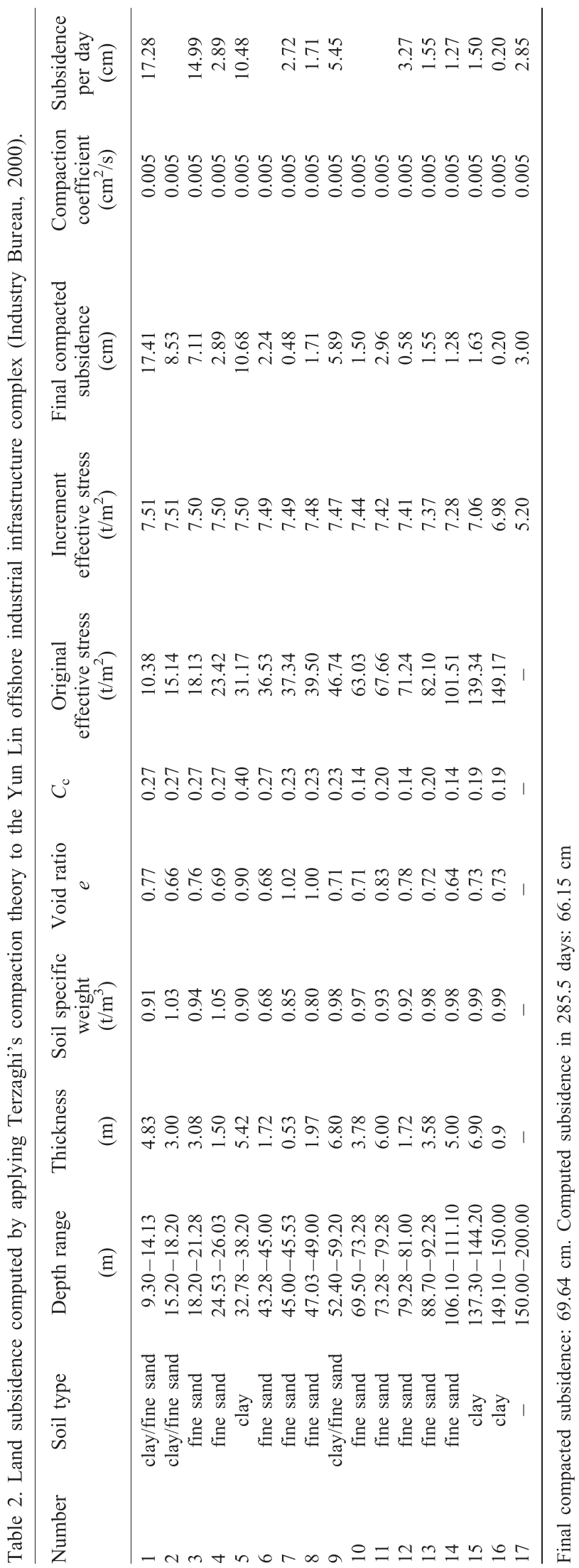




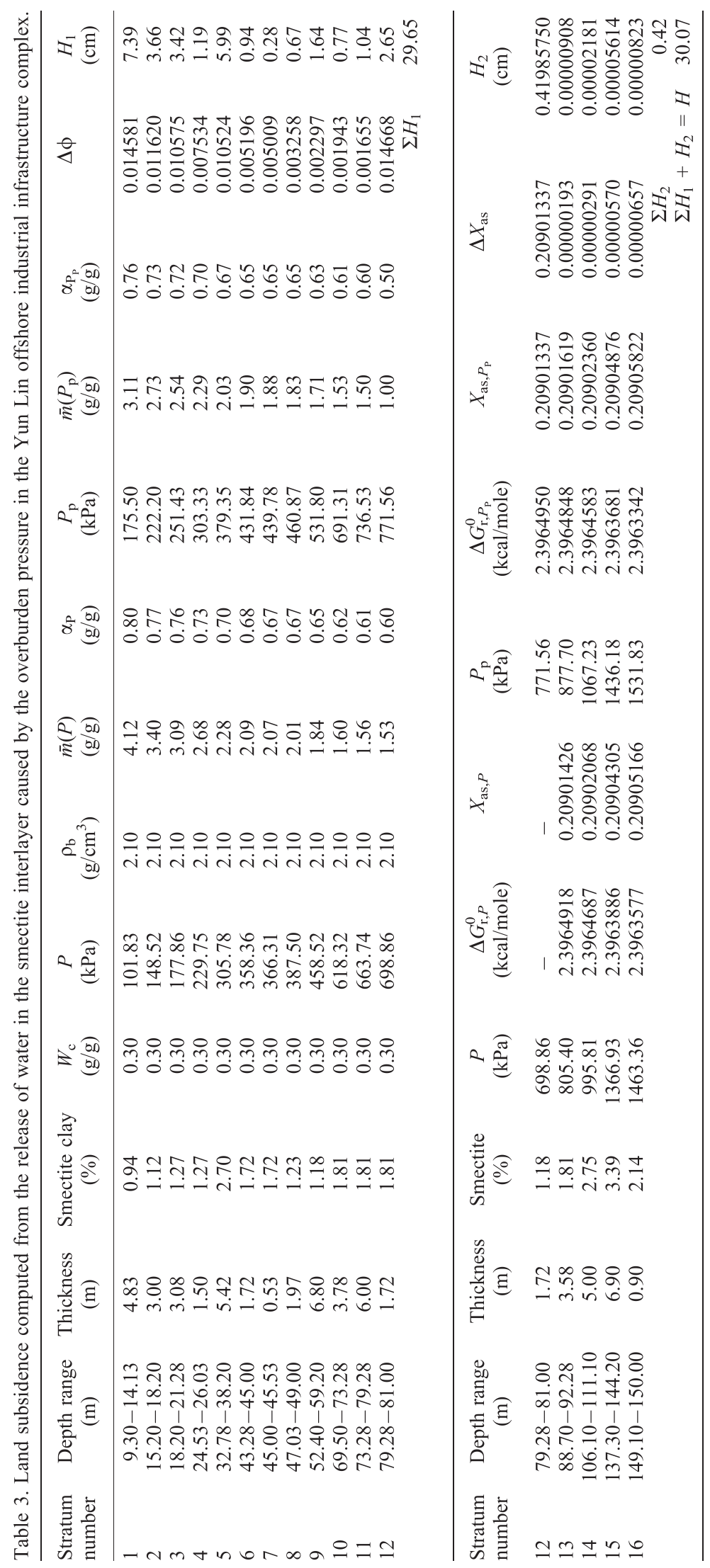


not sufficient to enable the release of water in the smectite interlayer in a deeper subsurface formation. Additionally, the data obtained at the multilevel land subsidence monitoring well from 1975 to 2000, and the benchmark measurements of the ground surface in 1975, 1989 and 2000 indicate that the accumulated land subsidence in Tai-Shi from 1975 to 2000 is $208 \mathrm{~cm}$. The estimated land subsidence due to smectite dehydration resulting from over pumping in Tai-Shi is $9.56 \%$ of the accumulated land subsidence measured in the field.

\section{CONCLUSIONS}

This study develops a novel smectite dehydration model of land subsidence in a shallow sedimentary basin. Based on the theory and experimental results for the swelling pressure, interlayer water content and the basal spacing taken from Oliphant and Low (1982), Zhang and Low (1989), and Fu et al. (1990), the solidsolution model of smectite dehydration developed by Ransom and Helgeson (1989, 1994a, 1994b, 1995), and the porosity correction relation of the hydrous smectite provided by Fitts and Brown (1999) and Brown and Ransom (1996), an evaluation model of the hydration state of smectite and a solid-solution model of smectite dehydration were formulated. The smectite dehydration model was applied to quantify the subsidence of land due to smectite dehydration in the Yun Lin offshore industrial infrastructure complex and the Tai-Shi area. The amount of subsidence attributed to smectite dehydration is determined using in situ stratigraphic data collected from the land subsidence monitoring well, the model of the hydration state of smectite and the solid-solution model of smectite dehydration.

The subsidence in the Yun Lin offshore industrial infrastructure complex at a depth of $200 \mathrm{~m}$, calculated using Terzaghi's compaction theory for primary consolidation at $2.5 \mathrm{y}$, stabilizes and reaches its final accumulated value of $69.40 \mathrm{~cm}$. However, the measured subsidence does not stabilize after $5 \mathrm{y}$. The difference between the measured and computed land subsidence is $32.75 \mathrm{~cm}$, and is close to the $30.07 \mathrm{~cm}$ of subsidence due to the dehydration of smectite. Including the effect of smectite dehydration yields a computed result that agrees with the field measurement. The computed results for subsidence due to smectite dehydration caused by the over-pumping of groundwater in Tai-Shi $(0-300 \mathrm{~m})$ is 19.88 , representing $9.56 \%$ of the accumulated subsidence measured in the field. The major land subsidence caused by smectite dehydration occurs in a shallow formation with a depth of 0 to $60 \mathrm{~m}$, whereas only a small amount of subsidence developed in a deeper formation $(>60 \mathrm{~m})$. The result reveals that smectite dehydration is of importance in assessing and predicting land subsidence in a shallow sedimentary basin.

Future work should address the kinetics of smectite dehydration, the development of the solid-solution model for smectite dehydration as a function of pressure and temperature in a radionuclear waste disposal site in which the backfill materials include smectite as a barrier, and an analysis of smectite dehydration due to the rapidly changing formation stress during fault displacement or an earthquake.

\section{ACKNOWLEDGMENTS}

The authors are grateful to the National Science Council, Republic of China, for financially supporting this research under contract No. NSC-90-2313-B-002-262.

\section{REFERENCES}

Anderson, D.M. and Low, P.F. (1958) The density of water adsorbed by lithium-, sodium-, and potassium-bentonite. Proceedings of the Soil Science Society of America, 11, 99-103.

Audet, D.M. (1995) Mathematical modeling of gravitational compaction and clay dehydration in thick sediment layers. Geophysical Journal International, 122, 283-298.

Bethke, C.M. (1986) Inverse hydrological analysis of the distribution and origin of Gulf coast-type geopressure zone. Journal of Geophysical Research, 91, 6535-3545.

Biot, M.A. (1941) General theory of three dimensional consolidation. Journal of Applied Physics, 12, 155-164.

Biot, M.A. (1955) Theory of elasticity and consolidation for a porous anisotropic solid. Journal of Applied Physics, 26, $182-185$

Brown, K.M. and Ransom, B. (1996) Porosity corrections for smectite-rich sediments-impact on studies of compaction, fluid generation. Geology, 24, 843-846.

Bruce, C.H. (1984) Smectite dehydration - Its relation to structure development and hydrocarbon accumulation in northern Gulf to Mexico Basin. American Association of Petroleum Geologists Bulletin, 68, 673-683.

Burst, J.F. (1969) Diagenesis of Gulf coast clayey sediments and its possible relation to petroleum migration. American Association of Petroleum Geologists Bulletin, 53, 73-93.

Central Geological Survey (1999) Project of groundwater monitoring network in Taiwan during first stage - Research report of Chou-Shui River alluvial fan: Water Resources Bureau Report, Ministry of Economic Affairs, ROC, 130.

Colten-Bradley, V.A. (1987) Role of pressure in smectite dehydration - Effects on geopressure and smectite-to-illite transformation. The American Association of Petroleum Geologists Bulletin, 71, 1414-1427.

Das, B.M. (1990) Principles of Geotechnical Engineering, $2^{\text {nd }}$ edition. PWS-Kent, Boston, USA, 350 pp.

Fitts, T.G. and Brown, K.M. (1999) Stress-induced smectite dehydration: ramifications for patterns of freshening and fluid expulsion in the N. Barbados accretionary wedge. Earth and Planetary Science Letters, 172, 179-197.

Foster, M.D. (1953) Geochemical studies of clay minerals, II: Relation between ionic substitution and swelling in montmorillonites. American Mineralogist, 38, 994-1006.

Fu, M.H., Zhang, Z.Z. and Low, P.F. (1990) Changes in the properties of a montmorillonite-water system during the adsorption and desorption of water: hysteresis. Clays and Clay Minerals, 38, 485-492.

Harward, M.E. and Brindley, G.W. (1966) Swelling of synthetic smectites in relation to lattice substitutions. Pp. 209-222 in: 13th National Conference of Clays and Clay Minerals Proceedings.

Hawkins, R.K. and Egelstaff, P.A. (1980) Interfacial water structure in montmorillonite from neutron diffraction experiments. Clays and Clay Minerals, 28, 19-28. 
Industry Bureau (2000) Yun Lin offshore industrial infrastructure complex development project, part IV: land subsidence monitoring and analysis. Industry Bureau Report, Ministry of Economic Affairs, ROC, 130.

Johnson, J.W., Oelkers, E.H. and Helgeson, H.C. (1992) SUPCRT92: Software package for calculating the standard molal thermodynamic properties of minerals, gases, aqueous species, and reactions among them as functions of temperature and pressure. Computers and Geosciences, 18 , 899-947.

Keren, R. and Shainberg, I. (1975) Water vapor isotherm and heat of immersion of $\mathrm{Na} / \mathrm{Ca}$-montmorillonite systems I: homoionic clay. Clays and Clay Minerals, 23, 193-200.

Keren, R. and Shainberg, I. (1980) Water vapor isotherm and heat of immersion of Na- and Ca-montmorillonite systems III: Thermodynamics. Clays and Clay Minerals, 28, 204-210.

Liu, C.W., Lin, W.S., Shang, C. and Liu, S.H. (2001) The effect of clay dehydration on land subsidence in Yun-Lin coastal area, Taiwan. Environmental Geology, 40, 518-527.

Low, P.F. (1979) Nature and properties of water in montmorillonite-water systems. Soil Science Society of America Journal, 43, 651-658.

Martin, R.T. (1962) Adsorbed water on clay - a review. Pp. 28-70 in: 9th National Conference on Clays and Clay Minerals Proceedings. Pergamon Press, New York.

Mitchell, J.K. (1993) Fundamentals of Soil Behavior, $2^{\text {nd }}$ edition. John Wiley and Sons, Inc., New York, 437 pp.

Mooney, R.W., Keenan, A.C. and Wood, L.A. (1952) Adsorption of water vapor by montmorillonite. Journal of the American Chemical Society, 74, 1367-1374.

Norrish, K. (1954) The swelling of montmorillonite. Faraday Society, London, Discussions, 18, 353-359.

Norrish, K. and Quirk, J.P. (1954) Crystalline swelling of montmorillonite: Use of electrolytes to control swelling. Nature (London), 173, 255-256.

Oliphant, J.L. and Low, P.F. (1982) The relative partial specific enthalpy of water in montmorillonite water systems and its relation to the swelling of these systems. Journal of Colloid and Interface Science, 89, 366-373.

Ormerod, E.C. and Newman, A.C.D. (1983) Water sorption on C3 saturated clays II; internal and external surfaces of montmorillonite. Clay Minerals, 18, 289-299.

Perry, E.A. and Hower, J. (1972) Late-stage dehydration in deeply buried pelitic sediments. The American Association of Petroleum Geologists Bulletin, 56, 2013-2021.

Posner, A.M. and Quirk, J.P. (1964) Changes in basal spacing of montmorillonite in electrolyte solution. Journal Colloid and Interface Science, 19, 789-812.

Powers, M.C. (1967) Fluid-release mechanism in compacting marine mudrocks and their importance in oil exploration. The American Association of Petroleum Geologists Bulletin, 51, $1240-1254$.

Ransom, B. and Helgeson, H.C. (1989) On the correlation of expandability with mineralogy and layering in mixed-layer clays. Clay and Clay Minerals, 37, 189-191.
Ransom, B. and Helgeson, H.C. (1994a) A chemical and thermodynamic model of aluminous dioctahedral 2:1 layer clay minerals in diagenetic processes: regular solution representation of interlayer dehydration in smectite. American Journal of Science, 294, 449-484.

Ransom, B. and Helgeson, H.C. (1994b) Estimation of the standard molal heat capacities, entropies, and volumes of 2:1 clay minerals. Geochimica et Cosmochimica Acta, 58, 4537-4547.

Ransom, B. and Helgeson, H.C. (1995) A chemical and thermodynamic model of aluminous dioctahedral 2:1 layer clay minerals in diagenetic processes: dehydration of diotahedral aluminous smectite as a function of temperature and depth in sedimentary basins. American Journal of Science, 295, 245-281.

Rowland, R.A., Weiss, E.J. and Bradley, W.F. (1956) Dehydration of monoionic montmorillonites. Pp. 85-95 in: Proceedings of the 4th National Conference on Clays and Clay Minerals, New York.

SYSTAT (2001) Table Curve 2D. Version 5.01, Systat Software Inc., Richmond, California.

Terzaghi, K. (1925) Erdbaumechanik auf bodenphysikalischer grundlage. Deuticke, Vienna, 399p.

van Olphen, H. (1963) Compaction of clay sediments in the range of molecular particle distances. Pp. 178-187 in: Proceeding of the 11th National Conference on Clays and Clay Minerals. National Academy of Sciences, National Research Council, Washington, D.C.

Water Resources Bureau (2001a) Land subsidence monitoring and analysis in Taiwan. Water Resources Bureau Report, Ministry of Economic Affairs, ROC, 900.

Water Resources Bureau (2001b) Analysis of the regional hydrogeological characteristics. Chou-Shui River alluvial fan: Water Resources Bureau Report, Ministry of Economic Affairs, ROC, 164.

Wu, T.C., Bassett, W.A., Huang, W.L., Guggenheim, S. and Koster van Groos, A.F. (1997) Montmorillonite under high $\mathrm{H}_{2} \mathrm{O}$ pressures: Stability of hydrate phases. Rehydration hysteresis, and the effect of interlayer cations. American Mineralogist, 82, 69-78.

Yasyerli, N., Doğu. G., Doğu, T. and McCoy, B.J. (1999) Pulse-response study for the humidity effect on sorption of ethyl bromide on clays. American Institute of Chemical Engineering Journal, 45, 291-298.

Zhang, F., Low, P.F. and Roth, C.B. (1995) Effect of monovalent, exchangeable cations and electrolytes on the relation between swelling pressure and interlayer distance in montmorillonite. Journal of Colloid and Interface Science, 173, 34-41.

Zhang, Z.Z. and Low, P.F. (1989) Relation between the heat of immersion and the initial water content of $\mathrm{Li}-, \mathrm{Na}$, and $\mathrm{K}$ montmorillonite. Journal of Colloid and Interface Science, 133, $461-472$.

(Received 9 October 2003; revised 1 July 2004; Ms. 842; A.E. Warren D. Huff) 